IZA DP No. 7300

Still Not Allowed on the Bus:

It Matters If You're Black or White!

Redzo Mujcic

Paul Frijters

March 2013 


\title{
Still Not Allowed on the Bus: It Matters If You're Black or White!
}

\author{
Redzo Mujcic \\ University of Queensland \\ Paul Frijters \\ University of Queensland \\ and IZA
}

\section{Discussion Paper No. 7300 \\ March 2013}

\author{
IZA \\ P.O. Box 7240 \\ 53072 Bonn \\ Germany \\ Phone: +49-228-3894-0 \\ Fax: +49-228-3894-180 \\ E-mail: iza@iza.org
}

Any opinions expressed here are those of the author(s) and not those of IZA. Research published in this series may include views on policy, but the institute itself takes no institutional policy positions. The IZA research network is committed to the IZA Guiding Principles of Research Integrity.

The Institute for the Study of Labor (IZA) in Bonn is a local and virtual international research center and a place of communication between science, politics and business. IZA is an independent nonprofit organization supported by Deutsche Post Foundation. The center is associated with the University of Bonn and offers a stimulating research environment through its international network, workshops and conferences, data service, project support, research visits and doctoral program. IZA engages in (i) original and internationally competitive research in all fields of labor economics, (ii) development of policy concepts, and (iii) dissemination of research results and concepts to the interested public.

IZA Discussion Papers often represent preliminary work and are circulated to encourage discussion. Citation of such a paper should account for its provisional character. A revised version may be available directly from the author. 


\title{
ABSTRACT \\ Still Not Allowed on the Bus: It Matters If You're Black or White!
}

\begin{abstract}
We employ a natural field experiment to study the extent and nature of racial discrimination in Queensland, Australia. Mimicking the historical case of Rosa Parks who was denied seating in a bus because she was black, an important moment for the U.S. civil rights movement, we sent trained testers who differed in ethnic appearance to bus stops asking the driver for a free ride on the basis that their bus pass was faulty (which it was). In total, we obtained 1,552 observations of testers either allowed a free ride or not, in each case recording the characteristics of the bus driver, the tester, and the circumstances. We find strong evidence of discrimination against black-skinned individuals. In the baseline scenario, white testers were accepted during $72 \%$ of the interactions versus only $36 \%$ for black testers. Indian testers were let on $51 \%$ of the time and Asian testers (mainly Chinese) were let on $73 \%$ of the time. Favors were more likely to be granted when the bus driver and tester were of the same ethnicity, and when there were fewer people in the bus. Patriotic appearance matters in that testers wearing army uniforms were accepted at a rate of $97 \%$ if they were white and $77 \%$ if they were black. Status appearance also mattered in that black testers dressed in business attire were just as likely to be favored as casually dressed white testers. When bus drivers were confronted with hypothetical baseline scenarios using photos taken of the real testers, $86 \%$ responded they would let on the black individual, more than double the actual number accepted, indicating dishonest self-reporting on this topic.
\end{abstract}

JEL Classification: $\quad \mathrm{C} 93, \mathrm{~J} 15, \mathrm{~J} 71, \mathrm{D} 03$

Keywords: racial bias, discrimination, natural field experiment, prosocial behavior

Corresponding author:

Paul Frijters

University of Queensland

School of Economics

Level 6, Colin Clark Building

St Lucia, Brisbane, Qld 4072

Australia

E-mail: p.frijters@uq.edu.au

*We thank Myra Yazbeck for helpful comments. 


\section{Introduction}

In 1955, Rosa Parks defied the legal restriction that black people had to give bus seating preference to white people, an act of civil disobedience that became a rallying cry for the U.S. civil rights movement. The choice of the white bus driver to enforce the rules of the company, rather than let Rosa Parks sit, was interpreted as an act of racism.

Sixty years on, despite the Civil Rights Act of 1964 and the election of the first black president of the United States in 2008, an active body of literature still investigates the presence of a 'taste for discrimination' and analyzes the channels via which this discrimination may affect individual choices and outcomes. ${ }^{1}$ Whilst most empirical studies find white males to have better market outcomes than others, such differences themselves may not necessarily be a consequence of any conscious dislike of one group by another, but rather the outcome of an economic calculus based on real differences between groups in market-relevant characteristics. This has lead to the use of natural field experiments in which the economic gains and losses are held constant, but where subjects have the discretion on whether or not to grant favors to people with different appearances. ${ }^{2}$

The present study recreates a facsimile of Rosa Parks' experience. Our setting is Queensland, Australia, which has gone through very similar legal changes as the American south. In 1955, black Aboriginals were not entitled to vote in Australia, and were only granted the vote in 1963. It still took 10 years after that for the 'white Australia policy' to end, under which only white immigrants were let into the country. Within Australia, the state of Queensland was the most vociferous opponent of this move towards legal equality and, similar to the U.S., the health and job market situation of non-whites in Queensland is considerably worse, raising the question whether there is still a remaining taste for discrimination in the public sector $3^{3}$

The natural field experiment we exploit is that of a bus driver who has the opportunity to provide a favor to an individual passenger that goes against company policy. In the baseline

\footnotetext{
${ }^{1}$ Altonji and Blank (1999) provide a general survey covering many decades of labor market research, with Lang and Lehmann (2012) discussing the more recent evidence. Fryer (2011) presents an overview of the persistent black-white gap in a number of socioeconomic outcomes, while Fryer and Katz (2013) examine the use of randomized experiments in measuring the effectiveness of public policy interventions on racial inequality.

${ }^{2}$ List and Rasul (2011) summarize the growing number of studies using field experiments to examine racial bias, and Zitzewitz (2012) reviews the forensic economic literature on this topic.

${ }^{3}$ The state of Queensland was also home to the anti-immigrant One Nation party of Pauline Hanson, garnishing $22.7 \%$ of the votes in the state elections of 1998. On current disparities, see the Australian Social Indicators report: http://www.socialinclusion.gov.au/sites/www.socialinclusion.gov.au/files/ publications/pdf/compendium-of-si-indicators.pdf.
} 
scenario, we assign trained testers (from different ethnic, gender, and age groups) to board public buses where they present an empty travel card and subsequently ask the bus driver if they can have a free ride to a bus stop that is an average distance away. Whilst the public bus company's official rules are not to provide a service free of monetary charge, we find that more than half of the monitored bus drivers do grant such a favor.

In a perfectly functioning market, we would not expect to observe any difference across racial/ethnic groups in services since those groups that get a worse treatment on average would turn to different providers. Becker (1957) defines racial discrimination in functioning markets as a 'taste for discrimination' wherein employers or clients receive a negative utility when employing or transacting with people from another race. Such a taste can predispose employers to reward black employees less than white employees for the same work. It could also influence customers as they might become less willing to pay a black supplier of a good or service. Becker argues that, in a perfectly functioning market economy, the non-discriminatory employers, including those of the same race, can undo the effects of the racist employers by setting up all-black firms, whilst intermediaries may overcome any bias amongst customers by minimizing contact between clients and black suppliers. Any remaining discrimination in perfectly competitive markets would then have to be due to actual observed or unobserved productivity differences rather than tastes.

The mechanisms via which productivity differences between whole groups can affect the treatment of individuals in both perfect and imperfect markets have been heavily researched since Becker (1957). For example, Knowles et al. (2001) point out that if blacks on average are more likely to be involved in crime, then it is an efficient use of finite police resources to put relatively more police monitoring on black individuals. Similarly, if black workers are on average less productive either due to lower productivity or simply due to greater difficulty in ascertaining their productive skills, then it becomes not just rational to prefer a non-black job applicant over an otherwise equivalent black one (Arrow 1973), but even to discriminate job applicants on black-sounding names $4_{4}^{4}$ Such statistical discrimination, in turn, may influence members of the targeted race in making prior life choices that reduce their later life productivity, making the discrimination self-fulfilling (see Fang and Moro (2011) for a survey of the many different theoretical mechanisms proposed).

The non-racist intermediaries can only overcome discriminatory tastes if it is possible and

\footnotetext{
${ }^{4}$ See Fryer and Levitt (2004) for a study that examines the effect of distinctively Black sounding names on individual economic and social outcomes.
} 
relatively costless to avoid direct contact. Thus, a true taste for discrimination can still have a real effect when there is some market failure that prevents non-discriminating intermediaries to arise between the discriminated group and the discriminating population. Prominent amongst the potential market imperfections that rule out intermediaries, are returns to scale that lead to single natural monopolies in human services catering simultaneously for the majority group as well as minority groups. The public sector constitutes a prime example of the aforementioned scenario. Since it is inefficient to duplicate basic public activities like policing or taxation, a taste for discrimination in the midst of public sector employees is hard to avoid for the individual members of a discriminated group as, by design, services are personal and allow only a limited role for intermediaries. More generally, the racism of the monopolizing group is hard to avoid in the presence of natural monopolies in important services, such as health, education, and public transport, for which the substitutes are imperfect. Legal institutions might prevent the racism from being overt, but cannot prevent racist tastes from having repercussions in situations where the service worker has discretion.

The situation of a bus driver being in a position to provide a favor to a stranger of a particular race and appearance allows us to examine whether there is a taste for discrimination without the confounding influence of many other factors. Primarily, there is no direct productive relation between the bus driver and potential passenger, meaning that any observed or unobserved productive characteristics should have no role in individual decisions. This is an advantage over other natural field experiments that involve either some work relation, such as job applications (e.g., Bertrand and Mullainathan 2004), or some degree of possible payment such as the interaction with taxi drivers (e.g., Balafoutas et al. 2012; Castillo et al. 2012).

Another advantage of our design is that the observed transaction is simple enough to ensure the repeated situations are comparable. Our testers were strictly instructed in what to say and also to refrain from emotive non-verbals, with random checks implemented by the experimenters in order to ensure that these instructions were followed. With around 32,000 different bus drivers employed in Queensland, 72.8 million individual bus trips recorded in 2012, and 63,000 weekly available bus services, it was possible to conduct a large number of repeated interactions without running the risk of substantially altering the aggregate environment for individual bus drivers or bus routes.$^{5}$ This advantage is not present in other field studies that

\footnotetext{
${ }^{5}$ These figures are obtained from official reports on public transport services in Brisbane (Queensland). The bus service and passenger turnover information can be found at: http://translink.com.au/resources/ about-translink/reporting-and-publications/2011-12-annual-report.pdf. The bus driver data is from: http://video. news. ninemsn. com. au: "Shocking bus driver figures revealed" (March 2012).
} 
involve a noticeable proportion of the (local) population, or require a lot of time.

The results show that bus drivers grant favors in almost $65 \%$ of all observed interactions. Our baseline treatment reveals that black and Indian testers are much less likely to be accepted by bus drivers than white Caucasian or Asian testers, and that, in general, bus drivers are more likely to provide favors to people of the same race or ethnicity as themselves. Given that the baseline treatment suggests an importance of in-group favoritism based largely on skin color, we then vary the circumstances of the situation in the direction of moving the members of the 'out-group' to the 'in-group'. One prominent hypothesis arising from the strong reciprocity arguments of Fehr et al. (2002) and Fong et al. (2006) is that 'in-groups' are partially based on expectations of general reciprocity towards others and society, giving a role for the appearance of wealth, trustworthiness, and group symbols. To this end, we implement two main experimental treatments. First, to ascertain the role of wealth and hence material status, we dress our testers in business suits and have them carry a briefcase, with the assumption that better dressed help-seekers are more likely to receive the favor. To see whether our black and Indian testers looked particularly threatening or untrustworthy, we additionally perform a random survey of the population whereby we ask passers-by to rate actual photographs of the testers by denoting a level of attractiveness, trustworthiness and aggressive appearance. Second, to ascertain the importance of group symbols, we allow testers to wear the national army uniform for a subset of interactions, where the army is very popular in Australia and soldiers are seen as defenders of the country.

As a follow-up to the field study, we conducted a complementary survey of random bus drivers at appropriate resting stations across the city. The survey depicted a hypothetical version of the same help-seeking scenario as that in the main study, whereby each bus driver was shown a color photograph of the real tester and asked if they would be willing to accept the person onto the bus without any monetary payment. The stated responses uncover the opposite to the actual behavior observed in the field: more black and Indian testers were given hypothetical free rides than white testers. When asked which reasons were most important for their decision, the least mentioned motive was whether the bus driver could relate to the help-seeker. Instead, official company rules were overly mentioned as the primary reason for denying a favor.

This paper contributes to the current literature on racial discrimination and natural field experiments by establishing the existence of a racial bias in face-to-face prosocial behavior amongst a particular group of public service providers. To our knowledge, this is the first 
such study on bus drivers' racial preferences since the Rosa Parks incident took place some sixty years ago, and the largest non-invasive natural field experiment involving public service providers to date. By observing the social interaction in a natural environment, varying the group characteristics, and performing follow-up surveys of the decision makers as well as the general population on key aspects of the choice scenario, we add to the few recent studies that combine field experimental data with survey evidence to uncover the individual psychology of the decision makers (see Balafoutas et al. 2012; Gneezy et al. 2012; Zussman 2012).

The rest of the paper proceeds as follows. Section 2 provides a brief overview of related studies. Section 3 describes the experimental design and participants in detail. In Section 4 we present the main results on the outcomes of majority and minority ethnic groups, as well as the overall level of in-group bias. The effects of our experimental treatments on any found racial bias are then discussed, followed by the results from the complementary survey of decision makers. Section 5 concludes.

\section{Related Literature}

Within economics, the group of studies that comes closest to identifying a taste for discrimination is that based on natural field experiments, where potential discriminators are observed in their natural environment and importantly are not aware of their participation (Harrison and List 2004). This experimental method can be divided into two leading forms: 'audit' and 'correspondence' studies.

In correspondence studies researchers create and send out fictional resumes to potential employers that have recently posted a vacancy, and then compare the associated call-back rates for particular demographic groups defined by gender, race, or ethnicity. Examples from both North America (Bertrand and Mullainathan 2004; Oreopoulos 2011) and Australia (Booth et al. 2012) confirm a strong employer preference for Caucasian names and profiles. An inherent disadvantage of these studies, however, is that in many instances it becomes quite difficult to rule out the presence of statistical discrimination. ${ }^{6}$ Also, without any face-to-face interaction between the employer and job applicant, the cues triggering discriminatory behavior are by necessity impersonal in correspondence studies. The emotional causes and effects of one-on-one discriminatory behavior observed by both the discriminator and recipient are then potentially

\footnotetext{
${ }^{6}$ See, for example, Bertrand and Mullainathan (2004) and List and Rasual (2011) for a more detailed discussion about this issue.
} 
quite different. Audit studies, on the other hand, involve assigned actors or testers transacting with targeted others in actual market and social settings; for example, by purchasing of a particular good or service (List 2004; Gneezy et al. 2012), or simply asking for some help (Gneezy et al. 2012).

To better understand the nature of discrimination, researchers have recently combined audit studies with specific field experimental treatments, taking any associated convergence in group outcomes as evidence of statistical rather than taste-based discrimination (see, e.g., List 2004; Doleac and Stein 2010; Castillo et al. 2012; Gneezy et al. 2012). Such studies have also minimized the potential for actor-induced bias (see Heckman 1998) by looking at very standardized interactions, such as seemingly unobserved charitable giving in the presence of different social cues (Andreoni et al. 2011; DellaVigna et al. 2012); bargaining and fraud in credence goods markets (Currie et al. 2011; Balafoutas et al. 2012; Castillo et al. 2012); and social discrimination in the marketplace (Gneezy et al. 2012).

Gneezy et al. (2012), for example, perform a series of natural field experiments to test for discriminatory behavior (across age, gender, race, sexuality, disability) in various market and social settings, including the car repair and sales markets as well as information markets. In the latter scenario, the authors monitor helping behavior on the city streets of Chicago in the form of strangers providing directions, picking up and returning misplaced pens or keys, and giving change for a dollar bill to the assumed help-seekers. Such standardized and short personal contacts allow the authors to minimize their reliance on the actors to behave the same across repeated interactions. Overall, Gneezy et al. report evidence of a racial bias towards black help-seekers as well as some indication of racial group loyalty, with the subjects being more likely to assist help-seekers of the same race. Using external data on criminal activity, the authors suggest the observed inferior treatment of black help-seekers to be potentially based on statistical motivations operating through perceptions of fear.

In the context of public services, the main findings on racial bias do not come from field experiments but rather naturally-occurring data, namely documented legal cases and police searches. Glaeser and Sacerdote (2003), Alesina and La Ferrara (2010), Shayo and Zussman (2011), and Anwar et al. (2012) look at the importance of the racial characteristics of defendants and jury compositions in the likelihood of convictions as well as the severity of punishments, with most of the studies finding a strong degree of in-group bias in the form of favoritism towards the own racial group. Similarly, Knowles et al. (2001), Anwar and Fang (2006), and Antonovics and Knight (2009) find evidence of same-race preferences elicited by 
police officers during motor vehicle stops and searches, with officers being significantly more likely to undertake a search if their own race and the motorist's race differ. The latter group of studies also shows mixed evidence of racial prejudice in the public sector.

Our implementation of a large-scale natural field experiment within the public sector adds to the above literature by combining the most desirable elements of the experimental method (randomization) and naturally occurring data (realism) to shed light on the existence and underlying source of racial discrimination among public service employees.

\section{Field Experiment}

\subsection{Experimental Design}

Our experimental design involved a set of testers who boarded a public bus in the city of Brisbane, Australia, in possession of a bus travel card with a preset balance of zero dollars. This 'Go' card (see Appendix A) would be blue in color, indicating that the holder was over 18 years old. After scanning an empty card on entrance, the ticketing system automatically displays a red flashing signal along with a loud sound that informs both the individual and the bus driver that the card is empty, requiring the individual to either pay for the intended trip in cash or otherwise exit the bus. At the time of the experiment, the price of the bus ticket was $\$ 4.50$ AUD for travel within a single zone of the city. The general social interaction is illustrated in Figure 1.

In our design, the testers made a solitary statement to the bus driver after scanning their travel card: "I do not have any money, but I need to get to the $[\mathrm{XX}]$ station". The 'XX' station would refer to a stop that was not within close walking distance for the individual, but around two kilometers away. This medium-range distance was chosen to avoid bus drivers rejecting testers due to the required traveling distance being either too short or too long. Following this statement, the bus driver is then left with a 'Let on / Do not let on' decision. If the tester is let on (accepted), he or she enters the bus and records this decision, along with a number of other observable subject and field characteristics. Otherwise, the tester exits the bus and records the same set of decision-related characteristics while waiting for the next bus to arrive.

Testers were given strict instructions to communicate the above statement using their normal-sounding voice, maintain an even demeanor, and not to argue over an unkind response or any other remarks made by the bus driver. To ensure consistency across testers, we 
employed undercover research assistants to observe selected interactions between the testers and bus drivers during their early and final interactions.

In terms of the legal situation, the employment agreement between bus drivers and their employee, the state government, forbids drivers to offer bus trips free of monetary charge, unless the individual is underage in which case the bus travel card has a different color than for overage passengers; meaning that the subjects could tell from the specific travel card used that our testers were not underage. A driver who allows a tester to board the bus without prior payment is then breaching his or her employment contract and displaying prosocial behavior.

Bus stations in Brisbane usually see new buses arrive every 5 to 15 minutes, and have multiple platforms and routes which individuals can take, making the waiting time of a 'rejected' tester relatively short and enabling them to record between 6 and 8 observations per hour. The testers were allowed to consider either a 'sequential' or 'circular' route when collecting the data, where testers can either travel solely between two bus stations or make a long circle departing and entering at many stations.

Testers were informed in smaller group meetings, during which they could only observe a few of the other testers, that they would be participating in "an experimental study" carried out by a group of economists, and were not made explicitly aware of our main objective of detecting racial discrimination. This avoids the common problem of audit studies that testers could go into the field and find what the researcher may have wanted them to find (see Heckman 1998).

Figures A2 and A3 of Appendix A present maps of the Brisbane city bus network, where around 78.2 million annual bus trips are made by travelers on 63,859 available weekly services, operated by the 32,000 registered bus drivers across the state region. Employed bus drivers are assigned a different bus route to follow on a daily basis as part of the internal roster system, adding further to the randomization of tester-subject interactions. Our field experiment was conducted within zones 1 to 4 (see Figure A3), with a majority of the interactions taking place inside the first three greater city areas (bounded by the suburbs of Chermside (North Brisbane), Sunnybank (South Brisbane), Carindale (East Brisbane), and Indooroopilly (West Brisbane)). Testers were shown several examples of bus trips and distances between particular stations that were acceptable for the study, after which they were assigned different bus routes and times to follow, with enough variation to capture different regions of the city and at the same time minimize the possibility of multiple testers encountering the same bus driver during the same period of time. Moreover, each tester was told to avoid approaching 
the same subject more than once. 7

\subsection{Participants}

In total, 29 testers participated in the field experiment between May 2011 and June 2012, consisting of students from various faculties at the University of Queensland in Brisbane as well as non-student members of the outside community. These individuals were recruited via announcements during lecture and tutorial classes, and by word-of-mouth from already participating friends. The average tester was 23.6 years of age, with the youngest and oldest person being 19 and 32 years old, respectively (see Table 1). In terms of racial/ethnic background, 6 of the testers were White (White- Australian, American, European); 12 were Asian (Chinese, Malaysian, Japanese); 6 were Indian (Sub-continental); and 5 were identified as Black (Indigenous Australian, African, African-American, Pacific Islander). There were 3 females and 3 males in the white group; 6 females and 6 males in the Asian group; 2 females and 4 males in the Indian group; and 2 females and 3 males in the black group.

In addition to the main decision variable, the testers recorded a set of observable bus driver and field characteristics. The former included the gender, perceived age, and race of the bus driver. The field-specific variables noted were the time of day (day or night), weather conditions (sunny, cloudy, raining), and an indicator of passenger numbers to proxy the degree of social scrutiny experienced by the decision maker. Table 1 summarizes these variables in more detail. As expected, the bus driving profession is male dominated, with only $16 \%$ of the sampled drivers being female. There were also slightly more mature-aged drivers present (59\%) than young ones (41\%). In regards to racial/ethnic background, the large majority of observed drivers were white (79\%); 10\% were Asian; 6\% were black; and 5\% were Indian.

Table 1 also contains subjective measures of tester appearance, which has been found in previous studies to have a marked effect on the behavior of agents in market transactions (Hamermesh 2011); namely tester beauty, aggression and trustworthiness. In terms of beauty, each tester was rated on a scale from 1 (very unattractive) to 7 (very attractive) by 40 random raters looking at a photograph of the tester. Raters were recruited amongst students and staff members on campus grounds at the University of Queensland. They were on average 24 years of age, and included 19 whites, 10 Asians, 7 Indians, and 4 blacks. Raters were also told to

\footnotetext{
${ }^{7}$ After interviewing each of the 29 testers, only two individuals stated that they had encountered the same driver on two separate occasions. These testers followed our instructions and did not board the given buses.
} 
consider a rating of 4 as the average level of beauty within the population, so as to ensure that they would vary their answers amongst the presented testers. To avoid any ordering effects on rater choices, the initial order of tester photographs was reversed for approximately half of the raters; where we subsequently find no statistical differences across mean ratings based on the order of presentation.

As reported in Table A1 of Appendix A, women received higher beauty ratings than men, and young testers were considered to be slightly better looking than older ones. At the same time, we find average ratings to be more variable across females than males. These findings are consistent with existing studies that make use of similar survey instruments and beauty measures (see e.g., Belot et al. 2012). Overall, white testers were rated as the most attractive (average rating of 4.39), while blacks were viewed to be the least attractive group (average rating of 3.54), a statistically significant difference at the $1 \%$ level. In terms of tester aggression, raters perceived men to be more aggressive than women, while blacks were deemed the most aggressive ethnic group. Similarly, white testers were judged to be slightly more trustworthy than black testers (0.67 vs. 0.61). Our expectations about the importance of these traits for bus driver decisions were that, given the usual fairly low degree of interaction between bus drivers and passengers, as well as the low overall degree of violence in Brisbane, trustworthiness and aggressive appearances should matter little. $]^{8}$

\subsection{Treatments}

We implemented two main treatments and realized an unanticipated price shock during the field experiment. The main experimental treatments concerned clothing, following the recognized effect of clothing on first impressions (Davis and Lennon 1988; Gilovich et al. 2010). By altering the clothing of our testers we aimed to manipulate the perceived income and patriotism levels of help-seekers. The resulting outcomes are then compared to the baseline treatment during which the testers wore plain casual clothing (t-shirt and shorts or jeans). To ensure comparability across different treatments, the same individual testers were used throughout each variation.

\footnotetext{
${ }^{8}$ The city of Brisbane, located in the south-eastern part of the state (Queensland), is ranked amongst the safer parts of the region as well as in comparison to other capital cities in Australia, with recorded offences against individuals at around 585 per 100,000 persons. See http://www.police.qld.gov.au/services/ reportsPublications/statisticalReview/1112/.
} 


\subsubsection{High Income}

In the high-income treatment, we asked selected testers from each racial/ethnic group to wear a business suit and carry a briefcase, indicating white-collar employment and higher socioeconomic status, which itself can also be seen as an informative signal of the productivity and trustworthiness of potential recipients. While there is laboratory evidence suggesting that unselfish subjects tend to mainly help low-income individuals in situations where trust plays little role (Fehr and Schmidt 1999; Bolton and Ockenfels 2000; Charness and Rabin 2002; Gantner and Kerschbamer 2011), the bus drivers in our context might be more concerned with whether or not they believe the testers and if they feel the tester belongs to the in-group, both of which are likely positively correlated with higher status (Frijters 2013).

\subsubsection{Patriotism}

We manipulate perceptions of help-seeker patriotism by having testers assume the role of members from the national defense force, i.e. wear a replica of the Australian army uniform. Such an explicit signal of membership to the country's defense institutions could motivate prosocial behavior in a number of similar ways. Firstly, it can be seen as a symbol of accepting the culture of Australia to the point of being willing to defend it, triggering a reciprocal response from the bus driver if the bus driver sees himself or herself as part of the protected group. Secondly, being employed by the national army is an informative signal about a person in that the army does not let in individuals with a major criminal history or mental imbalance $?^{9}$ In terms of how wearing an army uniform might affect the outcome gap between racial/ethnic groups, the first mechanism mentioned above would lead to a strong reduction in this gap as an army uniform would confer in-group status. The second would lead to a reduction in the racial gap proportional to the importance of the signal: the outcome gap should reduce more for black testers than for Indian and Asian testers who come from sub-populations with already very low crime rates.

\footnotetext{
${ }^{9}$ According to the Australian Bureau of Statistics (2012), criminal offenders born in Nigeria (Africa) have the highest imprisonment rate (1,079 prisoners per 100,000 adult population born in Nigeria) across Australia. The rate of imprisonment for Aboriginal and Torres Strait Islander prisoners was 14 times higher than the rate for non-Indigenous prisoners. Moreover, around one-third (32\%) of all Aboriginal and Torres Strait Islander prisoners were sentenced or charged for acts intended to cause injury. On the other hand, both the Indian and Asian groups have relatively low criminal conviction rates, lower than the rates for whites: less than $3.5 \%$ of all prisoners in Australia are of Asian or Indian origin, while more than $85 \%$ are white.
} 


\subsubsection{Increased Fares}

The final experimental variation was exogenous to our design and constituted a 15\% increase in public transport prices as of January 1, 2012. In theory, the higher fares should translate into lower acceptance rates by subjects due to the increased size of the implicit gift. To test for this, we compare tester outcomes before and after the price change.

\section{Results}

\subsection{Is there a racial bias in prosocial behavior?}

We obtained data on a total of 1,552 social transactions between the bus drivers (subjects) and our testers. Table 2 reports the mean acceptance rates for each tester and subject racial/ethnic group. The overall observed rate of acceptance is 64\%. This high level of generosity suggests a notable presence of social preferences. The top panel in Table 2 shows average rates of acceptance by tester group. White testers were let onto the bus in $77 \%$ of the cases, versus $43 \%$ for black testers, a difference that is statistically significant at the $1 \%$ level; suggesting a strong degree of discrimination against blacks. Indian testers were treated similarly to blacks with an acceptance rate of $57 \%$, also significantly less than white testers $(p=0.00)$. Asian testers were accepted $74 \%$ of the time, an insignificant difference with that of whites $(p=0.24)$.

The middle panel of Table 2 presents average levels of acceptance by subject race. Black bus drivers were on average the most generous group, accepting testers in $72 \%$ of the cases, compared to $54 \%$ by Indian bus drivers, and $64 \%$ by Asian and white bus drivers. The reported difference in generosity between black and white subjects is statistically significant at the $1 \%$ level.

In terms of other tester characteristics, we find slight evidence of a gender bias, with males being accepted $67 \%$ of the time compared to $59 \%$ for females, a difference that is significant at the $1 \%$ level ${ }^{10}$ Young testers were also favored over older testers ( 0.68 vs. $\left.0.53, p=0.00\right)$, but this should be taken with caution given the limited age range of our hired testers. As expected, testers who were rated as being somewhat aggressive received fewer acceptances on average

\footnotetext{
${ }^{10}$ There are no found differences in the level of generosity elicited by male and female bus drivers. In a postexperiment interview, however, many of our testers did note that female bus drivers were much more likely to express their anger and disappointment following a rejection; mainly reinforcing the fact that travelers must purchase a ticket before boarding the bus.
} 
than less-aggressive ones ( 0.57 vs. $0.69, p=0.00$ ), though perceived beauty had little effect. At the same time, more trustworthy help-seekers received a higher portion of acceptances than untrustworthy ones (0.69 vs. $0.60, p=0.00$ ).

In regards to the field variables, Table 2 shows that the acceptance rate is much higher on rainy occasions (87\%) than on sunny occasions (62\%). The acceptance rate is also around 10 percentage points higher at night time. Both when it rains and when it is dark, the value of the favor to the tester is likely to be seen as higher, even though the cost to the subject is the same, indicating the importance of prosocial considerations in these interactions. Interestingly, the average rate of acceptance is 0.11 higher under low social scrutiny than high social scrutiny ${ }^{11}$

In Table 3, we present levels of generosity by subject-tester racial/ethnic match. The diagonal entries capture interactions between testers and bus drivers of the same type. These probabilities are suggestive of racial group loyalty, with subjects always favoring testers of their own race/ethnicity over the others, except for bus drivers of black race who do not seem to differentiate help-seekers on the basis of race/ethnicity. More precisely, white subjects are found to discriminate against each of the three minority groups; Asian subjects mainly discriminate against testers of Indian and black race; Indian subjects only discriminate against testers of black race; while black subjects do not discriminate against any of the four racial/ethnic groups.

While the above descriptive results provide suggestive evidence of discrimination against blacks and Indians, as well as within-racial group loyalty, these summary statistics do not use the other information available about the transactions. The econometric specifications displayed in Table 4 and beyond are based on the following OLS regression:

$$
\text { Decision }_{i j}=\alpha+\beta R_{j}+\delta R_{i}+\gamma R_{i j}+\eta X_{i j}+\phi Z_{j}+\lambda T_{j}+\theta T_{j} \times R_{j}+\mu_{j}+\epsilon_{i j}
$$

where the dependent variable is an indicator for whether subject $i$ accepted tester $j$ onto the bus without any monetary fee. The vectors $R_{i}$ and $R_{j}$ contain indicators for subject and tester race/ethnicity, where 'white' is the reference (omitted) group, making the point estimate for $\beta$ directly interpretable as the estimated probability difference in acceptance between white

\footnotetext{
${ }^{11}$ Each bus vehicle is equipped with approximately 40 passenger seats. Thus, a 'low' level of social scrutiny captures the situation when the number of passengers is slightly below half of full seating capacity $(<15)$. On the other hand, the 'high' social scrutiny situation is recorded when close to half or more of the available seats are occupied $(\geq 15)$. Our choice of variable coding is based on simplifying the interpretations made by both our testers and the monitored bus drivers regarding passenger numbers.
} 
testers and the other groups, interpreted as racial bias. The indicator variable $R_{i j}$ takes on a value of one if the subject and tester are of the same race/ethnicity, and zero otherwise. Evidence of within-group loyalty is then captured by the point estimate for $\gamma$. The vector $X_{i j}$ captures other individual as well as shared subject and tester demographics, such as age, gender, tester beauty, aggression, and trustworthiness. The vector $Z_{j}$ includes a set of field-specific controls, namely the level of social scrutiny, time of day, and weather conditions. The various treatment indicators are contained in vector $T_{j}$, where the baseline (low income) treatment is the omitted category. Interactions between our experimental treatments and tester race/ethnicity are in the term $T_{j} \times R_{j}$ and are included in later results. Lastly, we allow for random effects via the term $\mu_{j}$ that may pick up elements idiosyncratic to the tester not already controlled for by the observed characteristics, such as an appearance of health or a particular facial expression.

Initial linear probability estimates are reported in Table 4, where the number of controls is gradually increased across each column to provide insights into the robustness of our results. The estimated probability of acceptance for black testers is approximately 47 percentage points lower than for white testers (first column), statistically significant at the $1 \%$ level, suggesting the presence of a large racial bias in observed generosity. Importantly, the estimated marginal effects of the race/ethnicity indicators do not change notably as we include extra controls for subject attributes and field characteristics. Contrary to the raw statistics, the econometric estimates imply there to be no significant differential treatment of Indian testers, relative to white testers $(p=0.30)$, indicating that the Indian testers had particularly bad draws on the control characteristics like social scrutiny and weather conditions.

The regression estimates in columns (2) and (3) of Table 4 indicate black bus drivers to be 14 percentage points more likely than white bus drivers to help testers, consistent with the descriptive results above. Moreover, there is some evidence of within-racial group loyalty, with the predicted probability of acceptance being around 6 percentage points higher for subject-tester pairs of the same race/ethnicity, compared to subject-tester pairs of different race/ethnicity (third column). This result is however only significant at the $10 \%$ level, but broadly in line with a number of related studies such as Antonovics and Knight (2009), Fong and Luttmer (2009), Shayo and Zussman (2011), Anwar et al. (2012), and Gneezy et al. (2012). The age of subjects also has a significant effect, with older bus drivers being on average 6 percentage points less prosocial than younger drivers.

When considering the other attributes of testers, both gender and age are found to be unim- 
portant for the predicted probability of acceptance shown in columns (1) and (2) of Table 4, although more mature testers had a 1.2 percentage point higher probability of being accepted based on the richer specification in column (3). Similarly, neither help-seeker attractiveness or aggression emerges as statistically significant across the specifications, implying that the initial differences in acceptance rates between higher and lower aggressive appearance (from Table 2) were driven by the fact that particular racial/ethnic groups were rated as more aggressive on average. But since the aggression variable attracts a large positive coefficient, we further examine in Table A2 of the Appendix how this individual trait interacts with tester race/ethnicity, revealing that the positive effect of aggression is mainly driven by the fact that the acceptance probability for aggressive black testers is more than two times higher than that of non-aggressive black testers ( 0.50 vs. $0.21, p=0.00)$, underscoring that it is not perceived aggressiveness that explains the difference in acceptance rates of blacks versus other groups.

On the other hand, tester trustworthiness has a positive impact on the probability of acceptance, with completely trustworthy help-seekers being as much as 57 percentage points more likely to be favored, relative to completely untrustworthy help-seekers; however the variation in this measured trait is rather low (standard deviation of 0.14). The estimated effect of trust is significant at the $1 \%$ level only in the full specification presented in column (3) of Table 4. Moreover, from the extended interaction results in Table A2, we see this effect to be particularly driven by differences within blacks and whites: the difference in mean acceptance rates between trustworthy and untrustworthy white testers is $0.36(0.93-0.57, p=0.00)$, while the same difference for black testers is equal to $0.28(0.54-0.26, p=0.00)$. Asian testers experienced a much smaller positive gap of $0.06(0.77-0.71, p=0.07)$, while untrustworthy Indian testers were accepted at a much higher rate than trustworthy ones $(0.66 \mathrm{vs.} 0.37$, $p=0.00$ ). Again, the latter raw statistic may well be due to Indian testers being exposed to relatively unfavorable and varying field measures.

Turning to the field characteristics in column (3) of Table 4, we find positive effects of worsening weather and daylight on the probability of acceptance. Each of these circumstances is estimated to increase the acceptance rate on average by 5 percentage points, implying that the probability of being given a favor is higher when the value of the favor to the person receiving it would be higher. The effect of social scrutiny is found to be negative, in that bus drivers act less prosocially by about 6 percentage points when many other passengers are watching, relative to situations when not many others are around. We explore the latter result in more detail below. 


\subsection{Does racial bias differ by treatment?}

In Table 5 we show the mean acceptance rates by treatment (top panel) and the rates of acceptance for different groups by treatment (bottom panel). Both the high income and patriotism treatments are found to significantly increase the level of acceptance. Testers involved in the high-income treatment experienced a notable increase in generosity relative to the baseline case: 0.81 versus 0.60 . This difference in means is statistically significant at the $1 \%$ level. Similarly, signaling a high degree of patriotism leads to testers receiving kindness in $89 \%$ of the interactions. There is no found importance for the size of the bus fares.

Comparing the acceptance rates across the two main treatments, we find that the average level amongst blacks increases from 36\% to $67 \%$ while wearing a business suit and carrying a briefcase, a difference that is significant at the $1 \%$ level. A similar increase is seen amongst Indians, from $51 \%$ to $83 \%$, whilst Asians experience a slight and insignificant drop from $73 \%$ to $69 \%$, and whites observe their acceptance rate to increase from $72 \%$ to $93 \%$. These changes could be consistent with statistical discrimination if blacks and Indians are considered to be less trustworthy, a signal that is then overcome by better clothing. In this vein, studies by Alesina and La Ferrara (2002) and Glaeser et al. (2000) find minority group membership and low socioeconomic status in terms of income and education to be associated with overall lower levels of trust. Also relevant is that Glaeser et al. report high-status individuals to elicit more trustworthiness in others. Nevertheless, our results in Table 4 already control for trustworthiness and reveal that the inclusion of trust (although important) does not significantly alter our estimate of the extent of racial bias.

The patriotism treatment leads to even higher observed levels of cooperation. Black testers report an acceptance rate of $77 \%$ when wearing the nation army uniform, while the remaining racial and ethnic groups each entail an acceptance rate of $90 \%$ or more. Indian testers realize a significant increase from $51 \%$ in the baseline treatment to $93 \%$ in the patriotism treatment. Asians were accepted at a rate of $90 \%$ when displaying a strong devotion to the country, while whites are found to be favored by subjects in almost every transaction at a rate of $97 \%$. As with the high-income treatment, these general increases could naively be thought to be commensurate with evidence of statistical discrimination when race is a signal of 'being a threat'. However, the particularly strong increase observed for Indian individuals (who have very low rates of crime) is not consistent with such a story. The pattern of changes in outcomes across the different races is more compatible with the hypothesis that an army suit is interpreted as 
an in-group signal by bus drivers. Nonetheless, there still remains a substantial gap between recipients of black and white race (77\% vs. $97 \%$ ), signifying that even a strong patriotic signal is not enough to overcome the racial bias.

Table 6 reports the parameter estimates for regressions that relate tester outcomes to the income and patriotism treatments, as well as the natural variation in the level of social scrutiny. In all cases, the specifications include added controls that correspond to the full-specification given in the final column of Table 4. Column (1) of Table 6 presents the main effects, where we find blacks to be 48 percentage points less likely to be favored than whites in the baseline treatment $(p=0.00)$, very similar to the results in Table 4 . The estimates also indicate highstatus testers to be on average 14 percentage points more likely to receive help, relative to low-status testers $(p=0.00)$. Moreover, the acceptance rate of patriotic testers is predicted to be 24 percentage points higher than for less patriotic ones $(p=0.00)$. We interpret these average treatment effects as demonstrating positive adjustments in bus driver perceptions, and that our outcome variable measures actual generosity and prosocial behavior, rather than some other motive or random noise.

The results in column (2) of Table 6 imply that the initial black-white acceptance gap of 0.48 does not change when black testers are dressed in business attire, with the estimated coefficient on High Income*Black Tester being insignificant at conventional levels. However, this point estimate does become statistically significant in the richer specification (final column), suggesting the racial bias toward blacks to be reduced by 21 percentage points, a finding that is consistent with the descriptive results. The manipulation of income is however still not enough to make bus drivers favor blacks over low-status whites. Similarly, we find testers of Indian ethnicity to realize a 17 percentage point increase in acceptances following the high-income treatment.

The estimates in column (3) indicate that the observed level of discrimination against blacks declines on average by 17 percentage points when black testers wear an army uniform, and by 13 percentage points for Indian testers. These estimated effects are significant at the $10 \%$ level.

\subsubsection{Effect of implicit monitoring on racial bias}

An important behavioral dynamic also of interest is how the above found racial bias varies with the level of implicit monitoring or social scrutiny. Previous studies, such as Parsons et al. (2011), find the level of racial discrimination elicited by professional baseball umpires 
to decrease in the number of implicit observers (namely, during well-attended and televised games). In the present context, social exposure of decision makers is approximated by the number of other passengers inside or waiting to board the same bus as our tester. From Table 2, we find the latter measure to have some impact on subject decisions: on average, testers were accepted during $67 \%$ of the low-scrutiny interactions (less than half-occupied bus), compared to $56 \%$ during high-scrutiny interactions (more than half-occupied bus). This difference is statistically significant at the $1 \%$ level.

Moreover, from the interaction results in column (4) of Table 6, we find that each non-white group is significantly less likely to be accepted by bus drivers when many others are watching, compared to situations when not many observers are present. The size of these (negative) marginal effects is around 0.14 and 0.18 for Asian and black testers respectively, while the effect is found to be strongest for Indian testers, who experience a 23 percentage point decline in their likelihood of acceptance $(p=0.00)$. On the other hand, white testers (the omitted group) have a 10 percentage point higher probability of being accepted when there are many onlookers $(p=0.05)$. Social scrutiny then in our context leads to more discrimination. These results also hold in column (5), where we estimate all treatment and race interaction effects simultaneously and find only slight changes in the magnitude and statistical significance of coefficients.

The above findings are suggestive of bus drivers altering their racial preferences further in favor of the majority group during periods of high implicit monitoring. Such a contrary finding to other decision-making environments (e.g., Price and Wolfers 2010; Parsons et al. 2011), where racial biases have been found to diminish in the number of observers, indicates the context under study to be of importance for understanding preferential behavior, and perhaps also that the type of onlooker matters: according to our testers, the vast majority of bus passengers are white across any of the bus routes used in our experiment ${ }^{12}$ Thereby, the observed tendency of bus drivers to increase their bias against minority 'out-group' members (especially, Indians) when under greater scrutiny, whilst increasing their favoritism towards white testers, could well reflect the preferences of the in-group observers.

\footnotetext{
${ }^{12}$ For privacy reasons and in order not to make bus drivers suspicious, our testers did not take photos of the interaction environment, which made it difficult for them to systematically ascertain the racial/ethnic mix of other passengers.
} 


\subsection{Complementary survey evidence}

To shed light on subject motives, we conducted a complementary survey of random bus drivers at appropriate resting stations across the city. The survey (contained in Appendix B) was implemented a few months after our main study and depicted a hypothetical version of the same help-seeking scenario as that observed during the field experiment. Each bus driver was shown a color photograph (identical to the one used for tester appearance ratings) of an actual tester dressed in casual clothing, and asked if they would be willing to let the person onto the bus without charging a monetary fee, again making it clear that the person's travel card was faulty. Following this choice, bus drivers were asked a set of sub-questions that aimed to capture the psychology behind an acceptance or rejection decision. More specifically, the respondents were asked to assign varying degrees of importance to specific statements relating to their perceptions of (1) help-seeker honesty; (2) the impact of their decision on other passengers; (3) the worthiness or merit of the help-seeker; (4) the propensity of the help-seeker to cause trouble or harm; and (5) the bus driver's ability to relate to the helpseeker in any way. An additional statement (6) was evaluated by those respondents who decided to reject the hypothetical help-seeker, which aimed to get at the significance that bus drivers assign to bus company policy. To cover our main aim of studying racial attitudes, we showed each participating bus driver only one hypothetical scenario involving a help-seeker from a single racial/ethnic group.

\subsubsection{Results}

We were only able to collect 108 complete responses before the above survey was boycotted by the bus company due to the type of ('prosocial') question being asked of their employees ${ }^{13}$ The race distribution of surveyed bus drivers was similar to that during the field experiment, with the vast majority of respondents being white (71\%); $12 \%$ were black; $9 \%$ were Asian; and $7 \%$ were of Indian origin. Similarly, most of the responding bus drivers were male (85\%).

Overall, the average stated level of acceptance was equal to $69 \%$, a result that is higher than the $60 \%$ observed in our baseline experiment $(p=0.00)$. Table 7 shows pairwise comparisons of acceptance rates (by group) across the two methodologies; 'actual' versus 'stated' generosity.

\footnotetext{
${ }^{13}$ Not long after our research assistants began conducting the survey, the bus drivers were strictly instructed by management not to participate in the survey any longer and thus rejected all consequent approaches. Such an outcome was consistent with bus drivers' work agreements which stipulate a set monetary price to be charged to all boarding adult passengers.
} 
The results suggest, in general, that the stated levels of generosity highly contradict the actual levels witnessed in the field. Foremost, there is no found racial bias toward the minority groups, with black and Indian individuals associated with the highest absolute rates of acceptance (0.86 and 0.76). Moreover, blacks are hypothetically accepted at more than twice the rate than in the main experiment: $86 \%$ versus $43 \%$. Despite the relative low number of responses, this difference is statistically significant at the $1 \%$ level, and highlights the role of subject awareness in decision making (see Bertrand and Mullainathan 2001). That is, during the selfreported artificial survey, bus drivers are well-aware that they are being studied by outsiders and hence alter their choice behavior.

Similarly, the survey results reveal no favoritism on the basis of gender, with men and women experiencing very similar rates of acceptance. This finding is also inconsistent with results from the field study during which our female testers received a significantly lower portion of positive responses than in the hypothetical situation (59\% vs. $72 \%, p=0.00)$. Older help-seekers are found to be favored at a rate of $75 \%$ in the hypothetical cases, whereas the same individuals are favored at a rate of $49 \%$ in the field $(p=0.01)$. Aggressive and untrustworthy help-seekers were also accepted more frequently in the hypothetical scenario than in the field.

Bus drivers of black race were still the most generous group, stating the highest relative level of acceptance (74\%), while white bus drivers are found to be much more generous during the artificial survey than in reality $(0.71$ vs. $0.60, p=0.02)$. Male survey respondents were significantly more prosocial than female respondents ( $72 \%$ vs. $56 \%$ ), a finding which also contradicts the gender-neutrality result reported earlier. Similarly, mature bus drivers were more giving in the artificial survey than in the field.

Consistent with bus drivers being both race and gender neutral in hypothetical situations, we find stated generosity to be specifically aimed at help-seekers from different ethnic and gender groups. Respondents are found to favor opposite ethnicities at a rate of $72 \%$ in the hypothetical situations, compared to only $56 \%$ in the real situations $(p=0.00)$. A very similar result and level of significance is found for opposite gender matches. Bus drivers' willingness to hide any in-group bias also emerges somewhat from the results, with same-race interactions being rewarded notably less in the hypothetical than the actual context ( 0.62 vs. 0.72 , respectively). This difference is however not significant at conventional levels $(p=0.13)$.

With regards to the stated reasons for accepting or rejecting testers, $83 \%$ of all the surveyed bus drivers indicated help-seeker honesty and ability to cause trouble as being at least 
'somewhat important', while 73\% of the respondents broadly judged the shown help-seeker on the basis of their worthiness. Around $65 \%$ of the surveyed bus drivers seemed to care about the impact of their decisions on other passengers, attaching some level of importance to the corresponding statement. On the other hand, the ability to relate to the help-seeker was pronounced not to have a major impact on bus driver choices, with $57 \%$ of respondents declaring this variable as strictly 'unimportant'.

Conditioning the above survey responses on the decision to accept a hypothetical helpseeker, we again find the decision maker's beliefs about individual honesty, worthiness, and propensity to cause problems as the characteristics which attract the highest levels of importance. Exactly 50\% of surveyed bus drivers labeled the perceived worthiness and propensity to cause trouble as 'very important' attributes which they look out for, while an additional 37\% and $40 \%$ of respondents viewed these respective traits as also being 'somewhat important'. Similarly, around $48 \%$ of bus drivers indicated perceived help-seeker honesty as being 'very important' for an acceptance. When eliciting stated generosity, around 17\% of respondents thought that it was 'very important' to consider how their decision would affect other passengers, while only $11 \%$ stated the ability to relate to the help-seeker as being 'very important' for acceptances.

If we further condition these hypothetical acceptances on recipient race, we find no significant differences in the value that respondents assign to the perceived merits of black and white help-seekers ( $p=0.65$ ), with the average levels of importance being equal to 2.45 and 2.59 (on a 1 to 3 scale) respectively. Similarly, bus drivers do not assign higher levels of importance to assumed recipient 'honesty' or 'ability to engage in trouble' when the help-seeker in question is of black race, compared to white race ( 2.00 vs. $2.40, p=0.20 ; 2.50$ vs. 2.53 , $p=0.91$ ). On the other hand, the subjects do seem to attach slightly higher average levels of importance to the approval of other passengers when accepting a white individual relative to a black individual (1.82 vs. $1.36, p=0.08$ ).

Due to the relatively small sample size at hand, we are unable to perform a similar betweengroup comparison exercise in regards to rejection decisions. However, the general findings on factors stated to be important for rejections are as expected: approximately, $91 \%$ of surveyed bus drivers identified their work agreement (of not allowing individuals to board a bus without a proper fare) to be of 'very high' importance when rejecting a help-seeker. At the same time, close to $50 \%$ of rejecting respondents felt that it was 'very important' for the help-seeker to be perceived as honest. Other issues of average importance for rejection decisions included the 
fear of upsetting or harming other passengers (73\% of bus drivers assigning at least 'somewhat importance'). Yet, whether the tester was an undeserving recipient was labeled as 'unimportant' by $73 \%$ of respondents. This apparent large difference between the latter finding and that for the same statement during hypothetical acceptances, where around $87 \%$ of bus drivers labeled 'perceived worthiness' as being important, seems likely driven by strong social desirability effects. That is, we believe the surveyed bus drivers were not willing to express their true beliefs about the merits of those individuals they rejected due to such responses directly revealing the type of person (defined by gender or race) that they would potentially discriminate or have prejudice against. In a similar vein, approximately $68 \%$ of bus drivers declare their 'inability to relate' to the given individual as being 'unimportant' for rejection decisions.

\section{Conclusion}

On December 1, 1955, in the south of the United States, Rosa Parks was denied a rule-defying favor by the white bus driver and instead had to endure a refusal. In this paper, we find that in present-day Queensland, Australia, black individuals are still more than 40 percentage points less likely than whites or Asians to be favored with a rule-defying free bus ride in situations when they do not posses a valid public travel card. With a business suit on and briefcase in hand, both blacks and whites are more likely to receive the favor, with the observed effect on black and Indian testers being particularly strong: an increase of around 30 percentage points in acceptance rates, compared to an average of only 10 percentage points for whites and Asians. The effects of wearing an army uniform are dramatic, with black and Indian testers suddenly let on more frequently than white testers without army uniforms. Even with such high signals of patriotism there still remains a significant black-white outcome gap; as almost 97\% of white individuals in an army uniform are favored and only $77 \%$ of black individuals.

In terms of the nature of this observed racial bias, we failed to find a consistent statistical discrimination explanation for the findings, with the two most important contenders being the possibility that bus drivers use race to approximate unobservable levels of criminality or dishonesty of the different groups. The notion that bus drivers are really just discriminating against blacks on the basis of the perceived levels of tester aggression fails three specific tests: (i) all found results are robust to including outsider-evaluated measures of aggressive appearance, (ii) Indian testers who come from a population that has much lower levels of criminal convictions than whites are almost equally discriminated in the baseline scenario as 
black testers and experience an equal average treatment effect when wearing an army uniform (where the national army selects against criminal convictions), and (iii) in the hypothetical scenarios bus drivers do not discriminate at all against blacks or Indians, whereas they should apply the same statistical discrimination to such hypothetical scenarios as in the field.

The notion that bus drivers are discriminating on whether or not they believe the tester to be lying to them is harder to dismiss at first glance. It is consistent with the strong increase in acceptance rates among Indian and black testers when wearing a business suit, as well as the stated importance of honesty within the hypothetical scenarios. Yet it does not explain why the treatment of groups differs over the type of bus driver, i.e. it would require for black bus drivers to not suspect anyone of being dishonest; Indian bus drivers to only dismiss blacks as dishonest; Asian bus drivers to view whites as the only honest group; and white bus drivers to suspect dishonesty among each of the three other groups.

The story that best fits the observations from our natural field experiment is that existing groups discriminate against members of racial/ethnic groups deemed less likely than them to be in the in-group, where clothing is taken as a visual cue of the degree to which particular individuals belong to this group. Discrimination of out-group members is then rationalized on the basis of following the rules and distrusting the motivations when not granting a favor, while believing in the honesty and general deservingness of the recipient when granting a favor. This is consistent with recent field studies examining both the extent and nature of racial discrimination in the United States and other countries (e.g., Shayo and Zussman 2011; Gneezy et al. 2012; Zussman 2012).

In terms of policy-relevance, our most important findings are that local social scrutiny is not found to lead to more racially equal prosocial behavior. On the contrary, a fuller bus is found to trigger higher levels of discrimination against the minority groups and greater favoritism towards the white group, most probably because the majority of on-looking passengers are also white, thereby increasing the importance of in-group behavior; a finding opposite to that of Parsons et al. (2011) who find increased levels of monitoring to reduce racial bias in umpire decisions. Commensurate with this, we do find that when bus drivers are asked by research assistants what they would do in hypothetical scenarios that they suddenly display gender and race neutral behavior. Combined, our findings thus cast doubt on the ability of greater social scrutiny by locals to reduce discriminatory behavior and, instead, leads to the thought that discrimination by public servants can be reduced either by changing the attitudes of the local groups or else by social scrutiny from outside. 


\section{References}

Alesina, A. and La Ferrara, E. (2002) Who Trusts Others? Journal of Public Economics, 85, 207-234.

Alesina, A. and La Ferrara, E. (2010) A Test of Racial Bias in Capital Sentencing, working paper.

Altonji, J. and Blank, R. (1999) Race and Gender in the Labor Market, in Ashenfelter, O. and Card, D. (Eds.), Handbook of Labor Economics, 3, 3144-3259, Amsterdam: Elsevier.

Andreoni, J., Rao, J., and Trachtman, H. (2011) Avoiding the Ask: A Field Experiment on Altruism, Empathy, and Charitable Giving, working paper.

Antonovics, K. and Knight, B. (2009) A New Look at Racial Profiling: Evidence from the Boston Police Department, Review of Economics and Statistics, 91, 163-177.

Anwar, S., Bayer, P., and Hjalmarsson, R. (2012) The Impact of Jury Race in Criminal Trials, Quarterly Journal of Economics, 127, 1017-1055.

Anwar, S. and Fang, H. (2006) An Alternative Test of Racial Prejudice in Motor Vehicle Searches: Theory and Evidence, American Economic Review, 96, 127-151.

Arrow, K. (1973) The Theory of Discrimination, in Ashenfelter, O. and Rees, A. (Eds), Discrimination in Labor Markets, 3-33, Princeton: Princeton University Press.

Australian Bureau of Statistics (2012) Prisoners in Australia, 2012, ABS cat. no. 4517.0, Canberra: ABS.

Balafoutas, L., Beck, A., Kerschbamer, R., and Sutter, M. (2012) What Drives Taxi Drivers? A Field Experiment on Fraud in a Market for Credence Goods, Review of Economic Studies, forthcoming.

Becker, G. (1957) The Economics of Discrimination, Chicago: University of Chicago Press.

Belot, M., Bhaskar, V., and van de Ven, J. (2012) Beauty and the Sources of Discrimination. Journal of Human Resources, 47, 851-872.

Bertrand, M. and Mullainathan, S. (2001) Do People Mean What They Say? Implications for Subjective Survey Data, American Economic Review, Papers and Proceedings, 91, 67-72. 
Bertrand, M. and Mullainathan, S. (2004) Are Emily and Greg More Employable than Lakisha and Jamal? A Field Experiment on Labor Market Discrimination, American Economic Review, 94, 991-1013.

Bolton, G. and Ockenfels, A. (2000) ERC - A Theory of Equity, Reciprocity and Competition, American Economic Review, 90, 166-193.

Booth, A., Leigh, A., and Varganova, E. (2012) Does Racial and Ethnic Discrimination Vary Across Minority Groups? Evidence from a Field Experiment, Oxford Bulletin of Economics and Statistics, 74, 547-573.

Castillo, M., R. Petrie, M. Torero, and Vesterlund, L. (2012) Gender Differences in Bargaining Outcomes: A Field Experiment on Discrimination, Journal of Public Economics, forthcoming.

Charness, G. and Rabin, M. (2002) Understanding Social Preferences with Simple Tests, Quarterly Journal of Economics, 117, 817-869.

Currie, J., Lin, W., and Zhang, W. (2011) Patient Knowledge and Antibiotic Abuse: Evidence from an Audit Study in China, Journal of Health Economics, 30, 933-949.

Davis, L. and Lennon, S. (1988) Social Cognition and the Study of Clothing and Human Behavior, Social Behavior and Personality, 16, 175-186.

DellaVigna, S., List, J., and Malmendier, U. (2012) Testing for Altruism and Social Pressure in Charitable Giving, Quarterly Journal of Economics, 127, 1-56.

Doleac, J. and Stein, L. (2010) The Visible Hand: Race and Online Market Outcomes, SIEPR Discussion Paper 10-025.

Fang, H. and Moro, A. (2011) Theories of Statistical Discrimination and Affirmative Action: A Survey, in Benhabib, J., Bisin, A., and Jackson, M. (Eds), Handbook of Social Economics, 1A, 133-200, North-Holland.

Fehr, E., Fischbacher, U., and Gächter, S. (2002) Strong Reciprocity, Human Cooperation and the Enforcement of Social Norms, Human Nature, 13, 1-25.

Fehr, E. and Schmidt, K. (1999) A Theory of Fairness, Competition, and Cooperation, Quarterly Journal of Economics, 114, 817-868. 
Fong, C., Bowles, S., and Gintis, H. (2006) Strong Reciprocity and the Welfare State, in Kolm, S. and Ythier, J. (Eds), Handbook on the Economics of Giving, Altruism and Reciprocity, 2, 1440-1464, Amsterdam: Elsevier.

Fong, C. and Luttmer, E. (2009) What Determines Giving to Hurricane Katrina Victims? Experimental Evidence on Racial Group Loyalty, American Economic Journal: Applied Economics, $1,64-87$.

Frijters, P. (2013) An Economic Theory of Greed, Love, Groups, and Networks, Cambridge University Press.

Fryer, R. (2011) Racial Inequality in the 21st Century: The Decline Significance of Discrimination, in Ashenfelter, O. and Card, D. (Eds), Handbook of Labor Economics, 4B, 855-971, Amsterdam: North Holland.

Fryer, R. and Katz, L. (2013) Achieving Escape Velocity: Neighborhood and School Interventions to Reduce Persistent Inequality, American Economic Review, Papers and Proceedings, forthcoming.

Fryer, R. and Levitt, S. (2004) The Causes and Consequences of Distinctively Black Names, Quarterly Journal of Economics, 119, 767-805.

Gantner, A. and Kerschbamer, R. (2011) Distributional Preferences, Risky Choices and Social Interaction Effects: Theory and Experiment, working paper.

Gilovich, T., Keltner, D., and Nisbett, R. (2010) Social Psychology, 2nd ed., New York: W. W. Norton.

Glaeser, E., Laibson, D., Scheinkman, J., and Soutter, C. (2000) Measuring Trust, Quarterly Journal of Economics, 115, 811-846.

Glaeser, E. and Sacerdote, B. (2003) Sentencing in Homicide Cases: The Role of Vengeance, Journal of Legal Studies, 32, 363-82.

Gneezy, U., List, J. and Price, M. (2012) Toward an Understanding of Why People Discriminate: Evidence from a Series of Natural Field Experiments, National Bureau of Economic Research Working Paper No.17855. 
Hamermesh, D. (2011) Beauty Pays: Why Attractive People Are More Successful, Princeton: Princeton University Press.

Harrison, G. and List, J. (2004) Field Experiments, Journal of Economic Literature, 42, 10091055.

Heckman, J. (1998) Detecting Discrimination, Journal of Economic Perspectives, 12, 101-116.

Knowles, J., Persico, N., and Todd, P. (2001) Racial Bias in Motor Vehicle Searches: Theory and Evidence, Journal of Political Economy, 109, 203-232.

Lang, K. and Lehmann, J. (2012) Racial Discrimination in the Labor Market: Theory and Empirics, Journal of Economic Literature, 50, 959-1006.

List, J. (2004) The Nature and Extent of Discrimination in the Marketplace: Evidence from the Field, Quarterly Journal of Economics, 119, 49-89.

List, J. and Rasul, I. (2011) Field Experiments in Labor Economics, Handbook of Labor Economics, Elsevier.

Oreopoulos, P. (2011) Why Do Skilled Immigrants Struggle in the Labor Market? A Field Experiment with Six Thousand Resumes, American Economic Journal: Economic Policy, 4, 148-178.

Parsons, C., Sulaeman, J., Yates, M., and Hamermesh, D. (2011) Strike Three: Discrimination, Incentives, and Evaluation, American Economic Review, 101, 1410-1435.

Price, J. and Wolfers, J. (2010) Racial Discrimination among NBA Referees, Quarterly Journal of Economics, 125, 1859-1887.

Shayo, M. and Zussman, A. (2011) Judicial Ingroup Bias in the Shadow of Terrorism, Quarterly Journal of Economics, 126, 1447-1484.

Zitzewitz, E. (2012) Forensic Economics, Journal of Economic Literature, 50, 731-769.

Zussman, A. (2012) Ethnic Discrimination: Lessons from the Israeli Online Market for Used Cars, Economic Journal, forthcoming. 




Figure 1: Social Interaction between Subject (Bus Driver) and Tester 
Table 1: Sample Participant and Field Characteristics

\begin{tabular}{|c|c|c|c|c|c|}
\hline Variable & Description & Mean & Std Dev & Min & $\operatorname{Max}$ \\
\hline \multicolumn{6}{|l|}{ Tester } \\
\hline Age & Years of Age & 23.73 & 3.95 & 19 & 32 \\
\hline Gender & $=1$ if Male & 0.64 & 0.48 & 0 & 1 \\
\hline Race & $\begin{array}{c}=1 \text { if White } \\
2 \text { if Asian } \\
3 \text { if Indian } \\
4 \text { if Black }\end{array}$ & 2.42 & 1.06 & 1 & 4 \\
\hline Attractiveness & $\begin{array}{l}=1 \text { if Very Unattractive } \\
7 \text { if Very Attractive }\end{array}$ & 3.94 & 0.68 & 2.80 & 5.35 \\
\hline Aggression & $=1$ if Aggressive & 0.12 & 0.09 & 0.03 & 0.48 \\
\hline Trustworthiness & $=1$ if Trustworthy & 0.65 & 0.14 & 0.35 & 0.95 \\
\hline \multicolumn{6}{|l|}{ Subject (Bus Driver) } \\
\hline Age & $=1$ if Mature & 0.59 & 0.49 & 0 & 1 \\
\hline Gender & $=1$ if Male & 0.84 & 0.37 & 0 & 1 \\
\hline Race & $\begin{aligned}= & 1 \text { if White } \\
& 2 \text { if Asian } \\
& 3 \text { if Indian } \\
& 4 \text { if Black }\end{aligned}$ & 1.38 & 0.84 & 1 & 4 \\
\hline \multicolumn{6}{|l|}{ Field Variables } \\
\hline Social Scrutiny & $=1$ if High & 0.26 & 0.44 & 0 & 1 \\
\hline Time of Day & $=1$ if Day & 0.89 & 0.31 & 0 & 1 \\
\hline Weather Conditions & $\begin{array}{r}=1 \text { if Sunny } \\
2 \text { if Cloudy } \\
3 \text { if Raining }\end{array}$ & 1.37 & 0.64 & 1 & 3 \\
\hline
\end{tabular}

Notes: Subjects (decision makers) are the bus drivers. Subject is defined as Young if perceived age < 45; Mature if perceived age $\geq 45$. Social Scrutiny is a proxy for the level of implicit monitoring experienced by subjects: 'High' if 15 or more other passengers were present (more than half-occupied bus). Racial/Ethnic groups are defined as: White (White- Australian, American, European); Asian (Chinese, Malaysian, Japanese); Indian (Subcontinental); Black (Indigenous Australian, African, African American, Pacific Islander). Each tester was rated on a scale from 1 (very unattractive) to 7 (very attractive) by 40 raters (balanced by gender). Raters also stated whether the tester (in the presented photograph) could be perceived as an 'aggressive' and 'trustworthy' individual. Attractiveness, Aggression and Trustworthiness of testers is averaged over raters. 
Table 2: Average Level of Acceptance by Group

\begin{tabular}{|c|c|c|}
\hline & Acceptance Rate & Test of Difference \\
\hline Overall $(N=1,552)$ & $0.64(0.48)$ & \\
\hline \multicolumn{3}{|l|}{ Tester } \\
\hline White $(n=366)$ & $0.77(0.42)$ & \\
\hline Asian $(n=485)$ & $0.74(0.44)$ & 0.24 \\
\hline Indian $(n=385)$ & $0.57(0.50)$ & 0.00 \\
\hline Black $(n=316)$ & $0.43(0.49)$ & 0.00 \\
\hline Male $(n=992)$ & $0.67(0.47)$ & \\
\hline Female $(n=560)$ & $0.59(0.49)$ & 0.00 \\
\hline Young $(n=1,155)$ & $0.68(0.47)$ & \\
\hline Mature $(n=397)$ & $0.53(0.50)$ & 0.00 \\
\hline Attractive $(n=679)$ & $0.63(0.48)$ & \\
\hline Unattractive $(n=873)$ & $0.65(0.48)$ & 0.40 \\
\hline Aggressive $(n=647)$ & $0.57(0.49)$ & \\
\hline Unaggressive $(n=905)$ & $0.69(0.46)$ & 0.00 \\
\hline Trustworthy ( $n=759)$ & $0.69(0.46)$ & \\
\hline Untrustworthy ( $n=793$ ) & $0.60(0.49)$ & 0.00 \\
\hline \multicolumn{3}{|l|}{ Subject (Bus Driver) } \\
\hline White $(n=1,227)$ & $0.64(0.48)$ & \\
\hline Asian $(n=150)$ & $0.64(0.48)$ & 0.96 \\
\hline Indian $(n=81)$ & $0.54(0.50)$ & 0.04 \\
\hline Black $(n=94)$ & $0.72(0.45)$ & 0.06 \\
\hline Male $(n=1,305)$ & $0.64(0.48)$ & \\
\hline Female $(n=247)$ & $0.64(0.48)$ & 0.94 \\
\hline Young $(n=634)$ & $0.66(0.47)$ & \\
\hline Mature $(n=918)$ & $0.63(0.48)$ & 0.06 \\
\hline \multicolumn{3}{|l|}{ Field Variables } \\
\hline High Scrutiny $(n=398)$ & $0.56(0.50)$ & \\
\hline Low Scrutiny $(n=1,154)$ & $0.67(0.47)$ & 0.00 \\
\hline Day $(n=1,379)$ & $0.63(0.48)$ & \\
\hline Night $(n=173)$ & $0.73(0.45)$ & 0.01 \\
\hline Sunny $(n=1,105)$ & $0.62(0.49)$ & \\
\hline Cloudy $(n=313)$ & $0.61(0.49)$ & 0.67 \\
\hline Raining $(n=134)$ & $0.87(0.34)$ & 0.00 \\
\hline
\end{tabular}

Notes: Acceptance Rate is the proportion of 'Yes' responses received (elicited) by testers (subjects). Tester is labelled as Young if age $<25$, Mature if age $\geq 25$; Unattractive if attractiveness $<3.94$, Attractive if attractiveness $\geq 3.94$; Unaggressive if aggression $<0.12$, Aggressive if aggression $\geq 0.12$; Untrustworthy if trustworthiness $<0.65$, Trustworthy if trustworthiness $\geq 0.65$, where the measures are averaged over raters. Subject is labelled as Young if perceived age $<45$, Mature if perceived age $\geq 45$. The number of observations per group is given by $n$. Standard deviations are shown in parentheses of the second column. Test of difference between sample proportions is based on $H_{0}: p_{1}=p_{2}$, where $p_{1}$ always corresponds to the first listed subgroup (White; Male; Young etc). The resulting $p$-values are reported in the third column. 
Table 3: Average Level of Acceptance by Racial/Ethnic Match

\begin{tabular}{|c|c|c|c|c|c|}
\hline & & \multicolumn{4}{|c|}{ Subject (Bus Driver) } \\
\hline & & White & Asian & Indian & Black \\
\hline \multirow{4}{*}{ 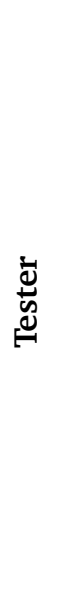 } & White & $\begin{array}{c}0.76(0.43) \\
n=301\end{array}$ & $\begin{array}{c}0.93(0.26) \\
n=28\end{array}$ & $\begin{array}{c}0.68(0.48) \\
n=19\end{array}$ & $\begin{array}{c}0.83(0.38) \\
n=18\end{array}$ \\
\hline & Asian & $\begin{array}{c}0.73(0.45) \\
n=407\end{array}$ & $\begin{array}{c}0.86(0.35) \\
n=36\end{array}$ & $\begin{array}{c}0.73(0.46) \\
n=15\end{array}$ & $\begin{array}{c}0.74(0.45) \\
n=27\end{array}$ \\
\hline & Indian & $\begin{array}{c}0.59(0.49) \\
n=320\end{array}$ & $\begin{array}{c}0.39(0.49) \\
n=44\end{array}$ & $\begin{array}{c}0.67(0.50) \\
n=9\end{array}$ & $\begin{array}{c}0.67(0.49) \\
n=12\end{array}$ \\
\hline & Black & $\begin{array}{c}0.38(0.49) \\
n=199\end{array}$ & $\begin{array}{c}0.52(0.51) \\
n=42\end{array}$ & $\begin{array}{c}0.37(0.49) \\
n=38\end{array}$ & $\begin{array}{c}0.68(0.48) \\
n=37\end{array}$ \\
\hline
\end{tabular}

NOTES: Each entry represents the mean acceptance rate conditional on tester and subject race/ethnicity. Standard deviations are shown in parentheses. The corresponding number of interactions observed is given by $n$ for each racial/ethnic pairing. 
Table 4: Effect of Observable Characteristics on the Probability of Acceptance

\begin{tabular}{|c|c|c|c|}
\hline \multirow{2}{*}{$\begin{array}{l}\text { Dependent Variable: } \\
\text { Accepted (Yes/No) }\end{array}$} & \multicolumn{3}{|c|}{ LPM Marginal Effects } \\
\hline & (1) & (2) & (3) \\
\hline \multicolumn{4}{|l|}{ Tester characteristics } \\
\hline Age & $\begin{array}{c}0.015 \\
{[0.011]}\end{array}$ & $\begin{array}{c}0.015 \\
{[0.013]}\end{array}$ & $\begin{array}{l}0.015^{* *} \\
{[0.006]}\end{array}$ \\
\hline Male & $\begin{array}{r}-0.010 \\
{[0.013]}\end{array}$ & $\begin{array}{r}-0.020 \\
{[0.116]}\end{array}$ & $\begin{array}{r}-0.009 \\
{[0.057]}\end{array}$ \\
\hline Asian & $\begin{array}{c}0.017 \\
{[0.108]}\end{array}$ & $\begin{array}{c}0.013 \\
{[0.122]}\end{array}$ & $\begin{array}{c}0.035 \\
{[0.062]}\end{array}$ \\
\hline Indian & $\begin{array}{r}-0.142 \\
{[0.138]}\end{array}$ & $\begin{array}{r}-0.148 \\
{[0.155]}\end{array}$ & $\begin{array}{r}-0.085 \\
{[0.075]}\end{array}$ \\
\hline Black & $\begin{array}{c}-0.465^{\cdots \cdots *} \\
{[0.143]}\end{array}$ & $\begin{array}{c}-0.471 * * * * \\
{[0.159]}\end{array}$ & $\begin{array}{c}-0.438 \cdots * \cdots \\
{[0.077]}\end{array}$ \\
\hline Attractiveness & $\begin{array}{r}-0.038 \\
{[0.082]}\end{array}$ & $\begin{array}{r}-0.045 \\
{[0.091]}\end{array}$ & $\begin{array}{r}-0.055 \\
{[0.042]}\end{array}$ \\
\hline Aggression & $\begin{array}{c}0.446 \\
{[0.588]}\end{array}$ & $\begin{array}{c}0.444 \\
{[0.654]}\end{array}$ & $\begin{array}{c}0.501 \\
{[0.312]}\end{array}$ \\
\hline Trustworthiness & $\begin{array}{c}0.497 \\
{[0.374]}\end{array}$ & $\begin{array}{c}0.492 \\
{[0.423]}\end{array}$ & $\begin{array}{l}0.567 * * * * \\
{[0.194]}\end{array}$ \\
\hline \multicolumn{4}{|l|}{ Subject characteristics } \\
\hline Age & & $\begin{array}{c}-0.063 * * * \\
{[0.023]}\end{array}$ & $\begin{array}{c}-0.060 * * * * \\
{[0.023]}\end{array}$ \\
\hline Male & & $\begin{array}{c}0.016 \\
{[0.031]}\end{array}$ & $\begin{array}{c}0.004 \\
{[0.032]}\end{array}$ \\
\hline Asian & & $\begin{array}{c}0.005 \\
{[0.037]}\end{array}$ & $\begin{array}{c}0.004 \\
{[0.037]}\end{array}$ \\
\hline Indian & & $\begin{array}{r}-0.047 \\
{[0.052]}\end{array}$ & $\begin{array}{r}-0.039 \\
{[0.053]}\end{array}$ \\
\hline Black & & $\begin{array}{l}0.135 * * * \\
{[0.050]}\end{array}$ & $\begin{array}{l}0.119 * * \\
{[0.048]}\end{array}$ \\
\hline Same Race & & & $\begin{array}{r}0.060 * \\
{[0.036]}\end{array}$ \\
\hline Same Gender & & & $\begin{array}{c}0.015 \\
{[0.032]}\end{array}$ \\
\hline \multicolumn{4}{|l|}{ Field characteristics } \\
\hline High Scrutiny & & & $\begin{array}{c}-0.055^{* * *} \\
{[0.027]}\end{array}$ \\
\hline Time of Day & & & $\begin{array}{r}-0.064 * \\
{[0.038]}\end{array}$ \\
\hline Weather Conditions & & & $\begin{array}{l}0.052^{* * * *} \\
{[0.018]}\end{array}$ \\
\hline Constant & $\begin{array}{c}0.156 \\
{[0.564]}\end{array}$ & $\begin{array}{c}0.221 \\
{[0.632]}\end{array}$ & $\begin{array}{c}0.180 \\
{[0.300]}\end{array}$ \\
\hline Tester Random Effects & $\checkmark$ & $\checkmark$ & $\checkmark$ \\
\hline Observations & 1,552 & 1,552 & 1,552 \\
\hline$R^{2}$ & 0.10 & 0.11 & 0.13 \\
\hline
\end{tabular}

NotEs: Linear probability model. Robust standard errors in parentheses. The dependent variable in all regressions is Accepted, an indicator variable that takes on a value of one if the subject accepted a tester. Same Race and Same Gender are indicator variables for subject and tester pairings that are of the same race and same gender, respectively. $*^{*},{ }^{* *}$, and ${ }^{* * *}$ indicate statistical significance at the $10 \%, 5 \%$, and $1 \%$ levels, respectively. 
Table 5: Level of Acceptance by Treatment




Table 6: Effect of Treatments on the Probability of Acceptance

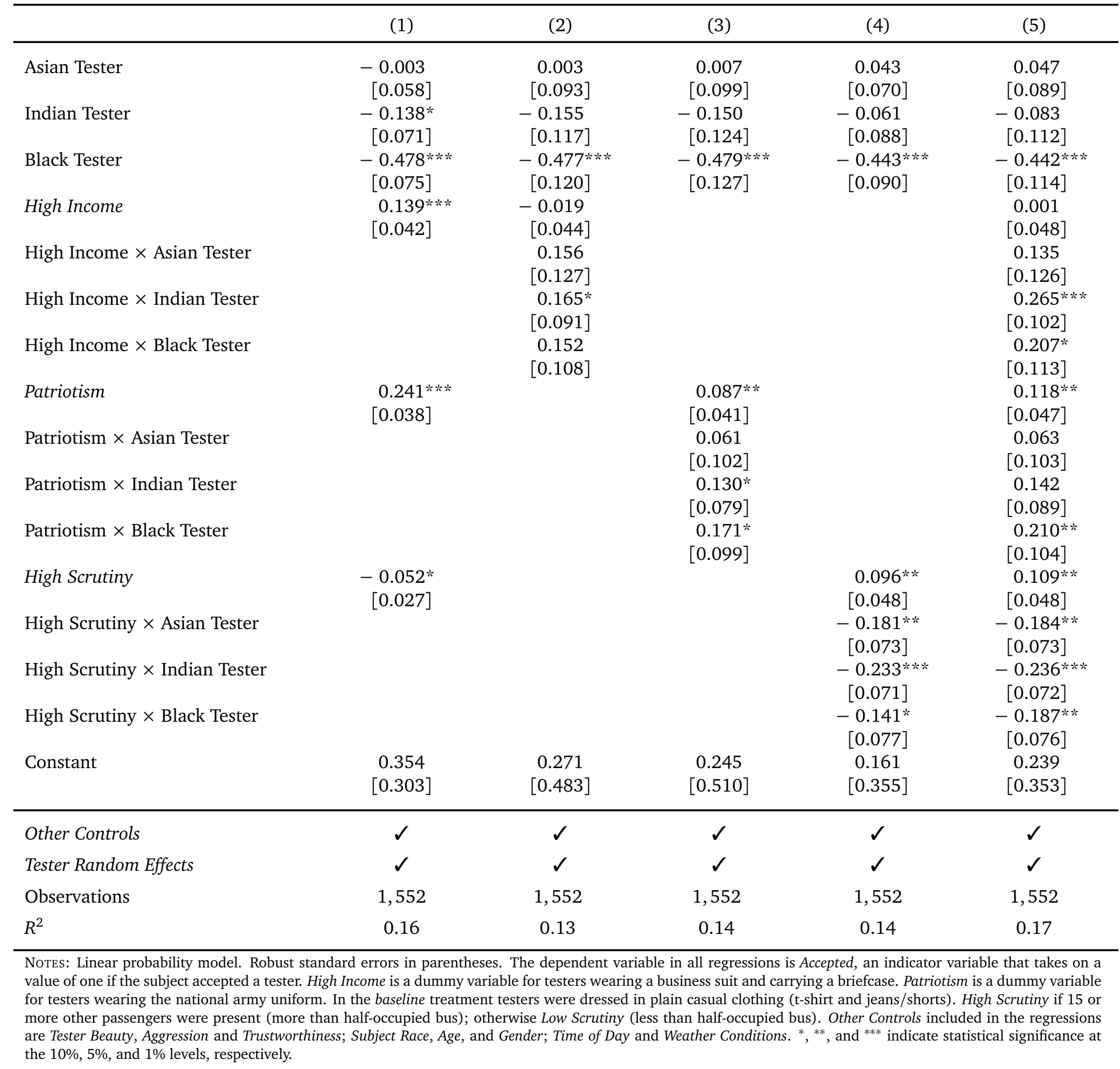


Table 7: Actual versus Stated Generosity

\begin{tabular}{|c|c|c|c|}
\hline & $\begin{array}{c}\text { Actual } \\
\text { Generosity }\end{array}$ & $\begin{array}{c}\text { Stated } \\
\text { Generosity }\end{array}$ & $\begin{array}{l}\text { Test of Difference } \\
\left(\widehat{p}_{\text {actual }}-\widehat{p}_{\text {stated }}\right)\end{array}$ \\
\hline Overall & 0.60 & 0.69 & 0.03 \\
\hline \multicolumn{4}{|l|}{ Tester } \\
\hline White & 0.72 & 0.67 & 0.28 \\
\hline Asian & 0.73 & 0.62 & 0.06 \\
\hline Indian & 0.51 & 0.76 & 0.01 \\
\hline Black & 0.36 & 0.86 & 0.00 \\
\hline Male & 0.60 & 0.67 & 0.15 \\
\hline Female & 0.59 & 0.72 & 0.04 \\
\hline Young & 0.64 & 0.68 & 0.20 \\
\hline Mature & 0.49 & 0.75 & 0.01 \\
\hline Attractive & 0.58 & 0.71 & 0.05 \\
\hline Unattractive & 0.62 & 0.69 & 0.13 \\
\hline Aggressive & 0.56 & 0.73 & 0.01 \\
\hline Unaggressive & 0.63 & 0.67 & 0.30 \\
\hline Trustworthy & 0.65 & 0.74 & 0.09 \\
\hline Untrustworthy & 0.56 & 0.66 & 0.07 \\
\hline \multicolumn{4}{|c|}{ Subject (Bus Driver) } \\
\hline White & 0.60 & 0.71 & 0.02 \\
\hline Asian & 0.57 & 0.50 & 0.34 \\
\hline Indian & 0.50 & 0.63 & 0.25 \\
\hline Black & 0.74 & 0.77 & 0.81 \\
\hline Male & 0.60 & 0.72 & 0.01 \\
\hline Female & 0.59 & 0.56 & 0.82 \\
\hline Young & 0.63 & 0.66 & 0.63 \\
\hline Mature & 0.58 & 0.74 & 0.02 \\
\hline Same Race & 0.72 & 0.62 & 0.13 \\
\hline Different Race & 0.56 & 0.72 & 0.00 \\
\hline Same Gender & 0.61 & 0.67 & 0.21 \\
\hline Different Gender & 0.58 & 0.73 & 0.02 \\
\hline
\end{tabular}

Notes: Actual Generosity is the proportion of 'Yes' responses received (elicited) by testers (subjects) in the baseline treatment of the actual field experiment. The values for each tester race/ethnicity are the same as those presented in Table 5 under the baseline treatment. Stated Generosity is the proportion of 'Yes' responses received (elicited) by testers (subjects) during the hypothetical survey. Tester is labelled as Young if age < 25 , Mature if age $\geq 25$; Unattractive if attractiveness $<3.94$, Attractive if attractiveness $\geq 3.94$; Unaggressive if aggression $<0.12$, Aggressive if aggression $\geq 0.12$; Untrustworthy if trustworthiness $<0.65$, Trustworthy if trustworthiness $\geq 0.65$, where the measures are averaged over raters. Subject is labelled as Young if perceived age $<45$, and Mature if perceived age $\geq 45$. Same Race and Same Gender are indicator variables for tester and subject pairings that are of the same race and same gender, respectively. Test of difference between sample proportions (across the two methodologies) is based on $H_{0}: p_{1}=p_{2}$, where $p_{1}$ corresponds to the acceptance rate observed during the actual field experiment, and $p_{2}$ corresponds to the acceptance rate stated during the hypothetical survey. The resulting $p$-values are reported in the third column. 


\section{A Additional Tables and Figures}

Table A.1: Summary of Tester Appearance Ratings

\begin{tabular}{|c|c|c|c|c|}
\hline & Mean & Std Dev & Min & Max \\
\hline \multicolumn{5}{|l|}{ Attractiveness } \\
\hline All $(N=29)$ & 3.94 & 0.66 & 2.80 & 5.35 \\
\hline Male $(n=16)$ & 3.65 & 0.51 & 2.80 & 4.55 \\
\hline Female $(n=13)$ & 4.44 & 0.55 & 3.60 & 5.35 \\
\hline Age $<25(n=22)$ & 4.02 & 0.61 & 2.85 & 4.98 \\
\hline Age $\geq 25(n=7)$ & 3.70 & 0.84 & 2.80 & 5.35 \\
\hline White $(n=6)$ & 4.39 & 0.64 & 3.50 & 4.98 \\
\hline Asian $(n=12)$ & 3.91 & 0.54 & 3.05 & 4.73 \\
\hline Indian $(n=6)$ & 3.86 & 0.58 & 2.85 & 4.58 \\
\hline Black $(n=5)$ & 3.54 & 0.98 & 2.80 & 5.35 \\
\hline \multicolumn{5}{|l|}{ Aggression } \\
\hline All $(N=29)$ & 0.12 & 0.10 & 0.03 & 0.48 \\
\hline Male $(n=16)$ & 0.13 & 0.12 & 0.03 & 0.48 \\
\hline Female $(n=13)$ & 0.09 & 0.07 & 0.03 & 0.20 \\
\hline Age $<25(n=22)$ & 0.10 & 0.09 & 0.03 & 0.35 \\
\hline Age $\geq 25(n=7)$ & 0.17 & 0.15 & 0.05 & 0.48 \\
\hline White $(n=6)$ & 0.12 & 0.12 & 0.03 & 0.35 \\
\hline Asian $(n=12)$ & 0.10 & 0.08 & 0.03 & 0.25 \\
\hline Indian $(n=6)$ & 0.08 & 0.06 & 0.03 & 0.18 \\
\hline Black $(n=5)$ & 0.20 & 0.16 & 0.08 & 0.48 \\
\hline \multicolumn{5}{|l|}{ Trustworthiness } \\
\hline All $(N=29)$ & 0.65 & 0.14 & 0.35 & 0.95 \\
\hline Male $(n=16)$ & 0.64 & 0.15 & 0.35 & 0.95 \\
\hline Female $(n=13)$ & 0.66 & 0.12 & 0.40 & 0.78 \\
\hline Age $<25(n=22)$ & 0.65 & 0.15 & 0.35 & 0.95 \\
\hline Age $\geq 25(n=7)$ & 0.62 & 0.11 & 0.40 & 0.75 \\
\hline White $(n=6)$ & 0.67 & 0.19 & 0.35 & 0.85 \\
\hline Asian $(n=12)$ & 0.67 & 0.15 & 0.48 & 0.95 \\
\hline Indian $(n=6)$ & 0.61 & 0.08 & 0.53 & 0.75 \\
\hline Black $(n=5)$ & 0.61 & 0.11 & 0.40 & 0.73 \\
\hline
\end{tabular}

NoTES: Each tester was rated on a scale from 1 (very unattractive) to 7 (very attractive) by 40 raters (balanced by gender). Raters also stated whether or not $(1 / 0)$ the tester (in the presented photograph) could be perceived as an 'aggressive' and 'trustworthy' individual. Attractiveness, Aggression and Trustworthiness of testers is averaged over raters. The number of individuals in each tester group is given by $n$. 
Table A.2: Average Level of Acceptance by Race/Ethnicity

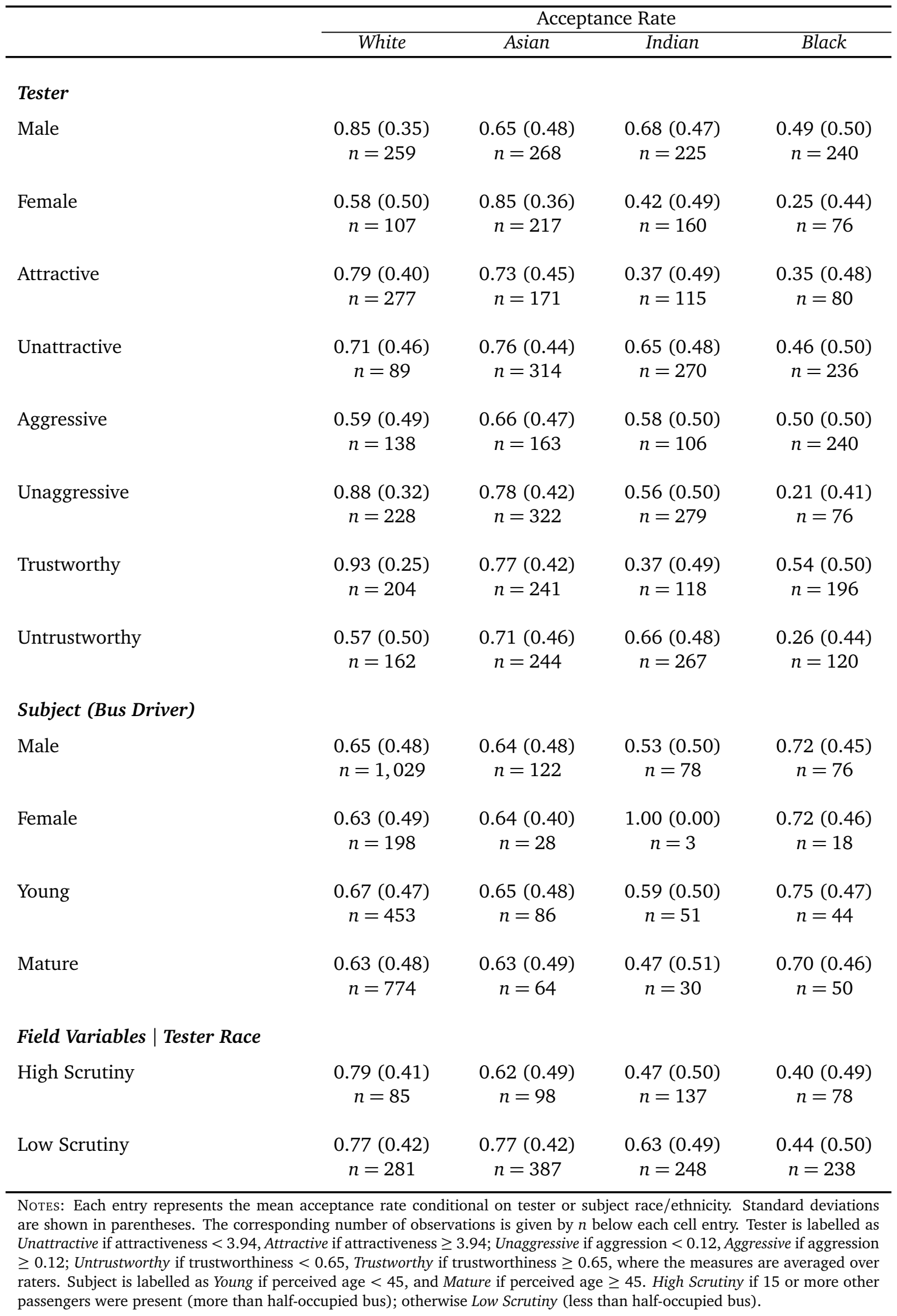




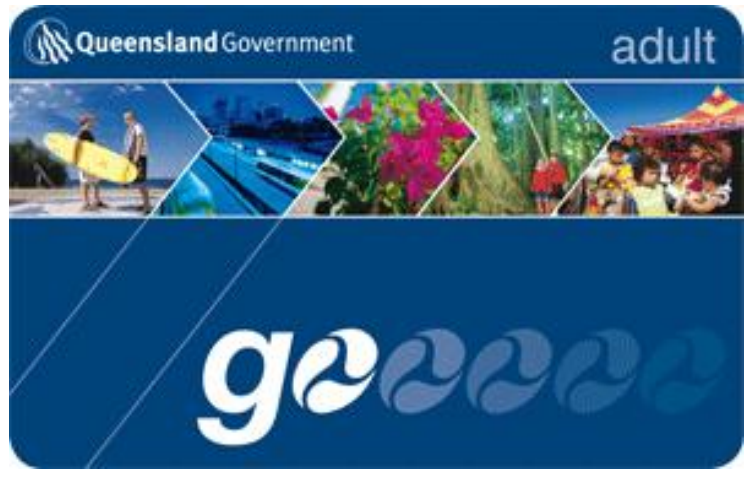

Figure A.1: Public Bus Travel ‘Go’ Card 


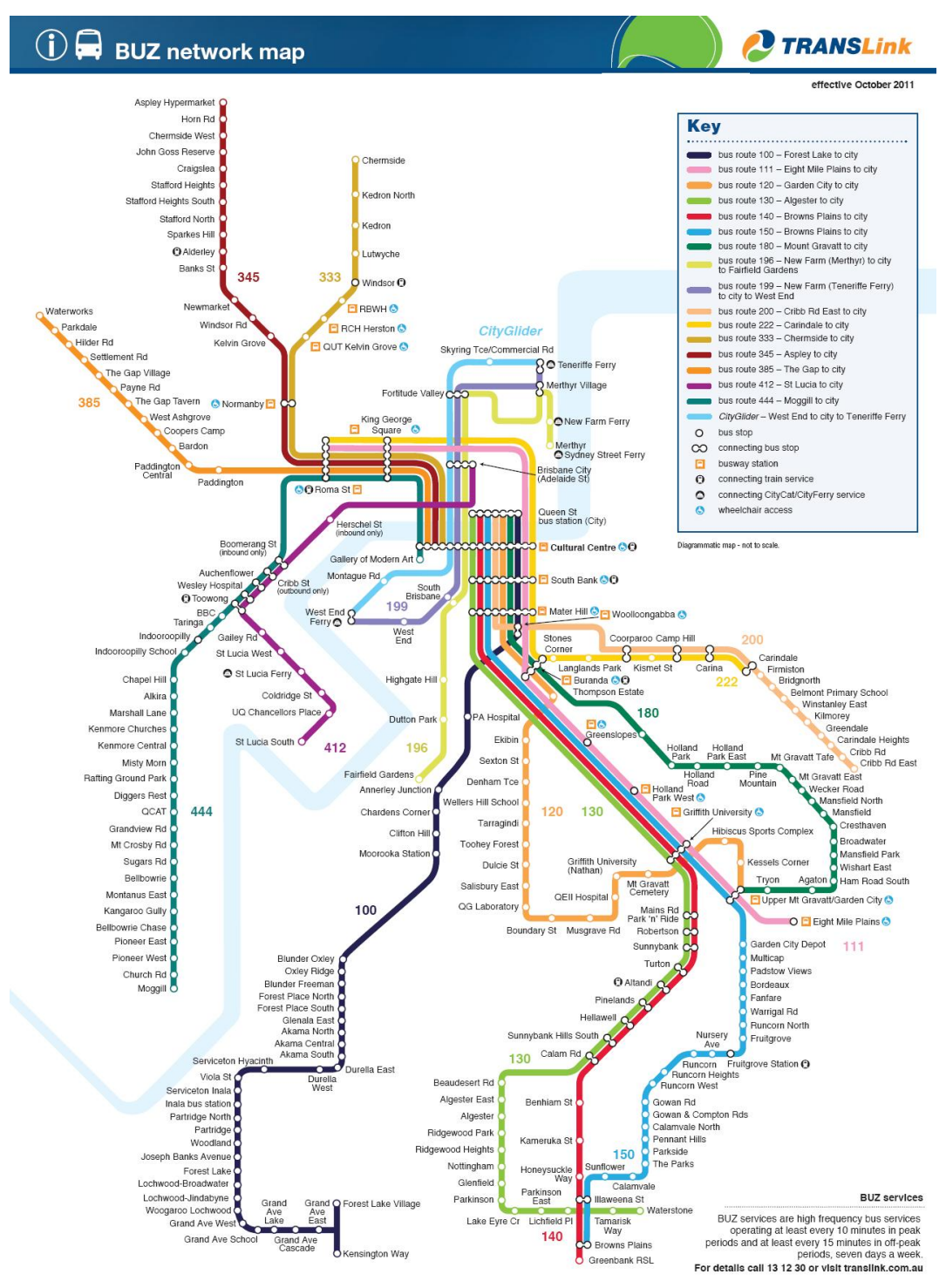

Source: www.translink.com.au

Figure A.2: Map of Brisbane City Bus Network 


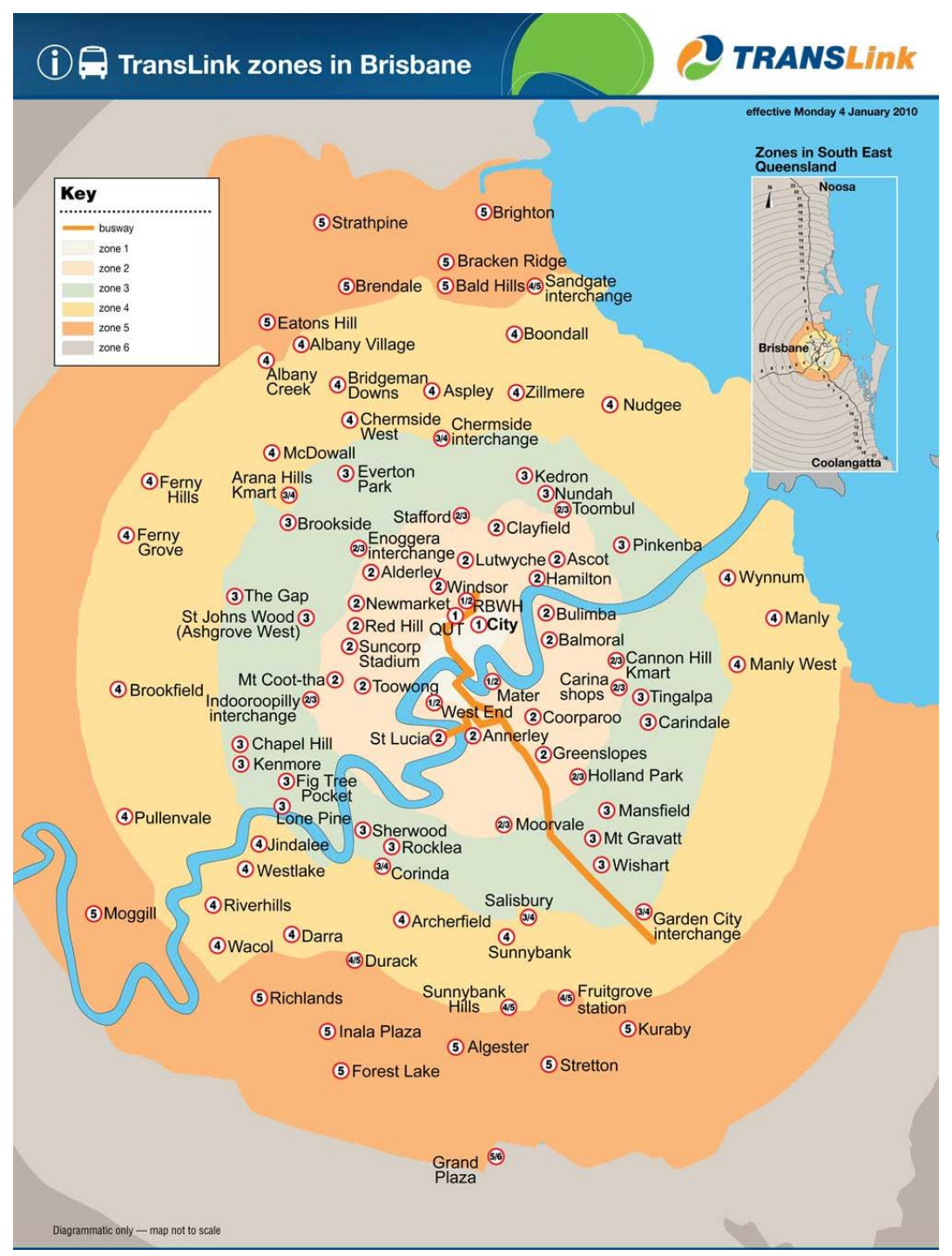

Source: www.translink. com.au

Figure A.3: Map of Data Collection Regions/Bus Zones 


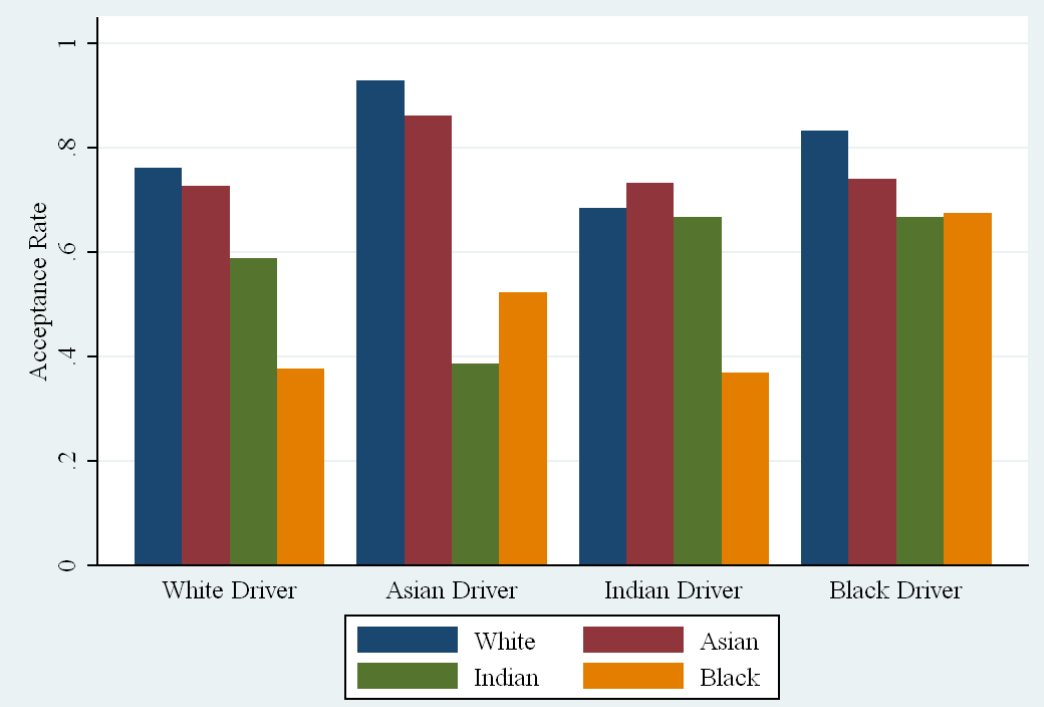

Figure A.4: Levels of Acceptance by Racial/Ethnic Match

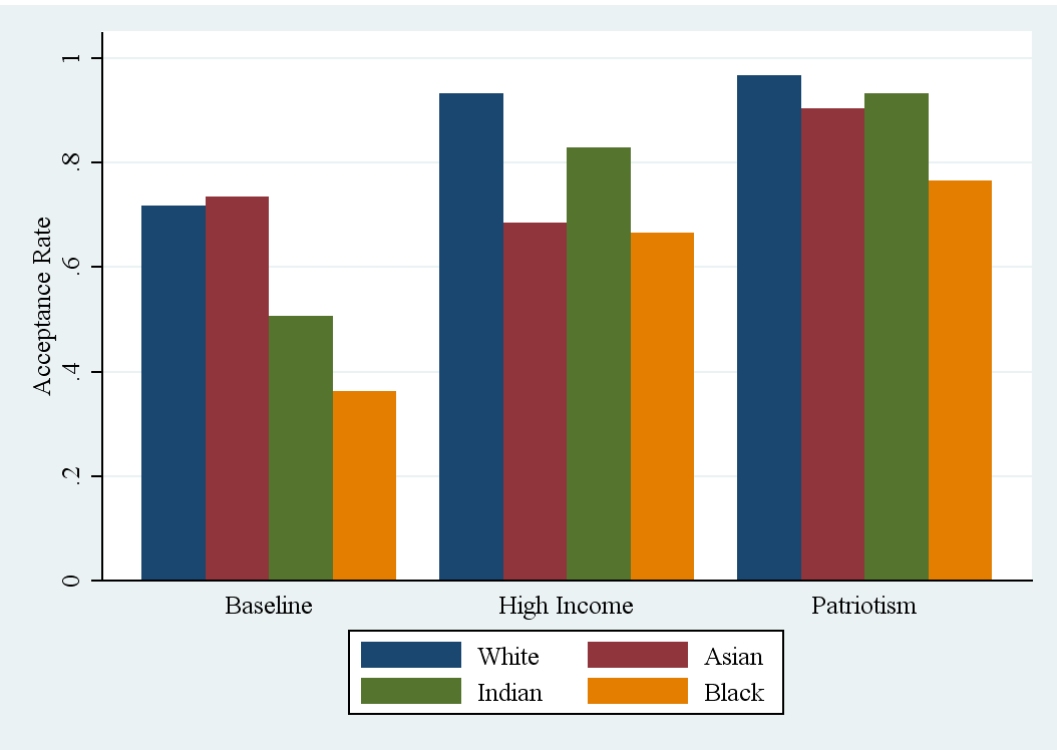

Figure A.5: Levels of Acceptance by Treatment 


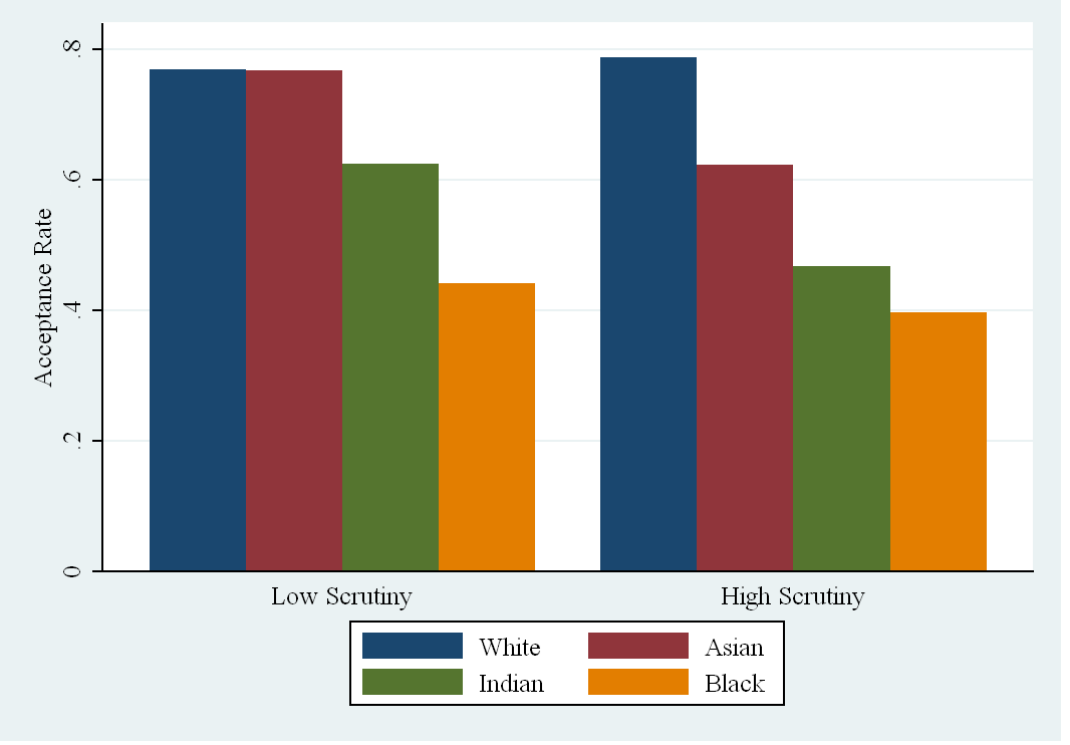

Figure A.6: Levels of Acceptance by Scrutiny 


\section{B Survey of Bus Drivers}

\section{Introduction}

Hello, my name is [ ], and I am a student/research assistant from the University of Queensland. I am doing some research on helping behavior in Brisbane, and was wondering if you could spare a few minutes to help me out with a few very simple questions? I will present to you a simple hypothetical scenario and would like to know your thoughts about it. The survey is totally anonymous and your responses will be used for research purposes only.

\section{Hypothetical Scenario}

- The following (adult) individual enters your bus.

- After scanning their Go Card, you find out that they have no travel balance.

- The person states that he/she does not have any money, but needs to get to the next station (which is not within close walking distance- around $2 \mathrm{~km}$ away).

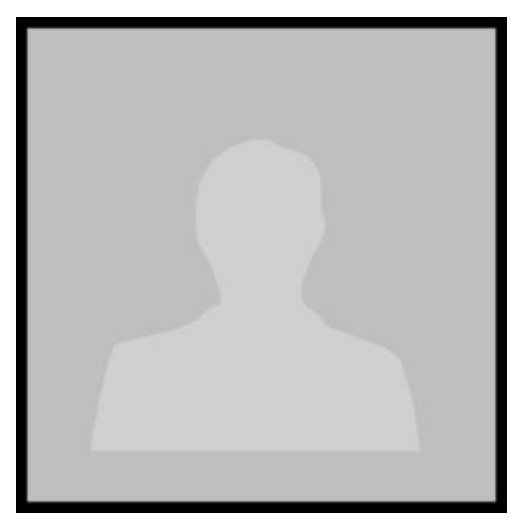

WOULD YOU BE WILLING TO LET THIS PERSON ONTO THE BUS?

YES / NO 


\section{If 'YES':}

\section{I would let this person on because:}

1. I would believe this person has made an honest mistake.

For me this is: [very important / somewhat important / unimportant]

$$
48 \% \quad 34 \% \quad 18 \%
$$

2. Other passengers would be OK with this.

For me this is: [very important / somewhat important / unimportant]

$$
17 \% \quad 46 \% \quad 37 \%
$$

3. This kind of person deserves some help.

For me this is: [very important / somewhat important / unimportant]

$$
\begin{array}{lll}
50 \% & 37 \% & 13 \%
\end{array}
$$

4. This person would be harmless if let on.

For me this is: [very important / somewhat important / unimportant]

$$
50 \% \quad 40 \% \quad 10 \%
$$

5. I can relate to this person.

For me this is: [very important / somewhat important / unimportant]

$11 \% \quad 36 \% \quad 53 \%$




\section{If 'NO':}

\section{I would not let this person on because:}

1. I would suspect this person is trying to get on for free and did not accidentally carry an empty Go Card.

For me this is: [very important / somewhat important / unimportant]

$$
50 \% \quad 38 \% \quad 12 \%
$$

2. It would upset other passengers if this person is let on.

For me this is: [very important / somewhat important / unimportant]

$$
23 \% \quad 50 \% \quad 27 \%
$$

3. This kind of person does not deserve help.

For me this is: [very important / somewhat important / unimportant]

$$
\begin{array}{lll}
0 \% & 27 \% & 73 \%
\end{array}
$$

4. This person might create trouble if let on.

For me this is: [very important / somewhat important / unimportant]

$$
27 \% \quad 32 \% \quad 41 \%
$$

5. I cannot relate to this person.

For me this is: [very important / somewhat important / unimportant]

$20 \% \quad 12 \% \quad 68 \%$

6. My work agreement/contract does not allow me to give away free bus rides.

For me this is: [very important / somewhat important / unimportant]

$$
\begin{array}{lll}
91 \% & 9 \% & 0 \%
\end{array}
$$

